\title{
A Solar Thermal Application for Mongolian Detached Houses: An Energy, Environmental, and Economic Analysis Based on Dynamic Simulations
}

\author{
Antonio Rosato ${ }^{1, *(1)}$, Purevdalai Erdenedavaa ${ }^{2}$ (D) Antonio Ciervo ${ }^{1}$, Atsushi Akisawa ${ }^{3}$, \\ Amarbayar Adiyabat ${ }^{2}$ and Sergio Sibilio ${ }^{1}$ \\ 1 Department of Architecture and Industrial Design, University of Campania Luigi Vanvitelli, \\ 81031 Aversa, Italy \\ 2 School of Engineering and Applied Science, National University of Mongolia, Ulaanbaatar 14201, Mongolia \\ 3 Graduate School of Bio-Applications and Systems Engineering, Tokyo University of Agriculture and \\ Technology, Tokyo 184-8588, Japan \\ * Correspondence: antonio.rosato@unicampania.it; Tel.: +39-081-501-0845
}

Received: 28 June 2019; Accepted: 7 August 2019; Published: 14 August 2019

\begin{abstract}
Ulaanbaatar (Mongolia) is the coldest capital city in the world with approximately $98 \%$ of its heating demand satisfied by means of coal-burning stoves. This leads to enormous air pollutant emissions, with Ulaanbaatar being one of the top five most polluted cities in the world. In this study, an innovative solar hybrid heating system for the Mongolian scenario was used, which was based on the operation of a solar field composed of four series-connected evacuated tube heat pipe collectors, coupled with a thermal energy storage. The solar hybrid heating system was simulated and analyzed using the software TRNSYS. The simulations were designed to satisfy the heating demand of a typical single-family detached house located in Ulaanbaatar and were carried out with and without considering the soiling effects on the solar system operation. The overall performance of the proposed plant was compared with those associated with different fossil fuel-based Mongolian conventional heating systems, in order to assess the potential energy, environmental and economic benefits. The results highlighted that the proposed plant allowed for the obtainment of significant reductions in terms of primary energy consumption (up to $34.6 \%$ ), global $\mathrm{CO}_{2}$ equivalent emissions (up to $52.3 \%$ ), and operating costs (up to $49.6 \%$ ), even if the expected return on the investment could be unacceptable.
\end{abstract}

Keywords: air pollution; harmful emissions; solar energy; energy saving; clean energy; dust deposition

\section{Introduction}

The use of raw coal for heating purposes in detached houses is still in practice, especially in cold regions. Mongolia is one of the coldest regions in the world and its heating demand during the winter is very relevant. In Mongolia, approximately $45 \%$ of the total population lives in the capital city of Ulaanbaatar; approximately $60 \%$ of the total households are located in the Ger districts of Ulaanbaatar, with approximately $98 \%$ of them using raw coal to satisfy the overall heating demand [1]. The significant use of raw coal during the winter leads to catastrophic air pollutant emissions, including carbon dioxide, sulphur dioxide, nitrogen oxides, and particulate matter, with Ulaanbaatar being one of the top five most polluted cities in the world [2]. The data collected by the Government of Mongolia highlighted how the pollution levels were several times higher than the recommended daily average concentration, with very serious potential health consequences (particularly for children) [2]. 
Given the considerable negative impact of air pollution, greater efforts are needed to prevent and treat the health impacts in Ulaanbaatar. A holistic approach to tackle the issue is mandatory, urging stakeholders to invest not only in immediate measures to reduce the impacts of air pollution on health, but also in cleaner energy solutions to be adopted in a sustainable way.

In Ulaanbaatar, the most economically and technically feasible solution to be implemented for replacing the coal-based heating systems is using an electric heater. However, this option has the following disadvantages [3]:

1. Electric heaters increase the electric peaks demand by a significant amount during the cold period causing frequent blackouts, which are currently one of the most relevant problems in Mongolia [4].

2. The annual current expenses associated with the use of electric heaters are relatively high for people who live in a detached house, in comparison with those associated with the adoption of a coal-burning stove.

3. The maximum power load for households in the Ger districts of Ulaanbaatar is generally lower than $4 \mathrm{~kW}$ [5]. Therefore, using a fully electric heating system would require upgrading the power level supplied by the local electric utility to the end-users.

4. Centralized power plants in Mongolia use coal to produce electricity, which implies that the application of electric heaters does not contribute to the reduction of global $\mathrm{CO}_{2}$ equivalent emissions (even if it decreases the local air pollution), in comparison to distributed coal-burning stoves with a greater conversion efficiency.

Solar energy, as a pollution-free, inexhaustible, and affordable energy resource, is considered one of the most promising options for both energy-saving as well as the reduction of harmful emissions at global and local levels. However, the Mongolian government is not strongly supporting solar thermal systems, mainly because of the huge investments involved. In addition, it should be highlighted how there is a significant lack of studies that have assessed the operation of such systems in cold regions (even though the performance of solar applications is greatly affected by climatic conditions). With reference to this last point, it can be noticed how a demonstration house in Ulaanbaatar that optimized solar energy gains by incorporating energy efficient techniques and passive solar elements into its design was built and analyzed by Dawes et al. [6]. A solar heating system integrated with a thermal energy storage tank filled with a phase-change material and combined with finned heat pipes was developed for Mongolian cities by Bai et al., who then also experimentally studied these systems [7]. Mori and Kawamura [8] investigated the performance of a solar water heating system combined with a heat-pump unit from both experimental and simulation points of view, while operating in a cold region. Therefore, the review of the current literature shows how the exploitation of solar energy for heating purposes in cold regions has been poorly investigated and additional studies are required to explore its potential.

Numerous studies have analyzed and compared the performance of different types of solar collectors, which have highlighted how evacuated tube collectors are more appropriate in cold and harsh regions, when compared to other technologies [9-12]. However, Ayompe et al. [13] have stated that the on-site thermal performance of the evacuated tube solar collectors has yet to be well-investigated, especially in cold and harsh cities. There are three common types of evacuated tube solar collectors [14]-(a) water-in-glass evacuated tube solar collectors, (b) U-type evacuated tube solar collectors, and (c) evacuated tube heat pipe solar collectors. In comparison to the other types of evacuated tube collectors, evacuated tube heat pipe collectors show a reduced efficiency, but lower pressure drops and, in addition, are easier to install and maintain [15-17].

Several external factors relating to the geographical location and environmental conditions can have a significant impact on the performance of a solar-energy system. Among them, soiling is a commonly overlooked or underestimated issue that can be a bind for the viability of a solar installation. The reduction in solar intensity reaching the solar converter due to the soiling effect has been evaluated 
and documented over the past five decades, and this reduction can typically be in the range of $20 \%$ to $50 \%$, or even more [18]. Several analyses have been carried out to evaluate the soiling effect on the performance of photovoltaic systems [19-21] and flat plate collectors [22-24], however, studies focusing on evacuated tube collectors are relatively poor. El-Nashar [25] investigated the impact of dust deposition on two evacuated tube collector blocks (with each block consisting of 168 panels connected together in a series/parallel arrangement) and found that the daily amount of heat collected by a dusty block could drop to $60 \%-70 \%$ of its initial value, if left without cleaning for a whole year. El-Nashar [26,27] also assessed the influence of dust deposition on the operating performance of a solar desalination plant in Abu Dhabi from the experimental and simulation points of view. The results showed that distillate production can drop by approximately $40 \%$ when the transmittance of the glass tubes drops from its clean condition value of 0.98 to a very dusty value of 0.70 . An empirical correlation for calculating the reduction in light transmittance has been identified. No studies investigating the effects of dust deposition on the performance of evacuated tube solar thermal collectors operating in cold areas with a great deal of air pollution (such as Mongolia) are available in current literature, except the work performed by the authors [28] where a method capable of predicting the dust deposition rate and the related change in transmittance of glass tubes, using weather data, has been developed and validated based on long- and short-term experimental tests performed in Ulaanbaatar.

In this paper, a solar hybrid heating system mainly consisting of: (i) A sensible thermal energy storage with a single internal heat exchanger; (ii) a solar field composed of four series-connected evacuated tube heat pipe collectors thermally interacting with the tank through the internal heat exchanger; (iii) an auxiliary electric heater immersed in the storage; (iv) a low-pressure coal-burning stove has been modelled, simulated and analyzed by means of the commercial TRaNsient SYStems (TRNSYS) software platform (version 17) [29]. The system is devoted to satisfying the heating demand of a typical single-family detached house situated in the Chingeltei Ger district of Ulaanbaatar city in Mongolia during the entire heating season. The simulations were performed also considering the effects of dust deposition on the overall performance of the solar system by means of a method able to predict the dust deposition rate and the related change in transmittance of glass tubes developed and validated by the authors based on long- and short-term experimental tests performed in Ulaanbaatar.

The results have been compared with those associated with different fossil fuel-based conventional heating systems (representative of solutions commonly used in Mongolian residences) in terms of: (a) Primary energy consumption; (b) consumption of coal; (c) global carbon dioxide equivalent emissions; (d) operating costs according to the Mongolian scenario.

The main aims of the paper can be summarized as follows:

1. To propose an innovative solar thermal system for Mongolian applications potentially capable of mitigating the energy, environmental and economic effects of traditional Mongolian heating systems;

2. To develop a simulation model to predict the performance of the proposed solar thermal system in Mongolia under different operating conditions and control logics;

3. To assess the feasibility of using solar thermal collectors during the heating period for Mongolian applications;

4. To estimate the degrading effects of dust deposition on the glazing of solar thermal collectors on the overall performance of the proposed heating plant;

5. To assess the potential benefits associated with the proposed plant with respect to the current Mongolian scenario from energy, environmental and economic points of view.

The final simulation results highlighted how, in comparison to the Mongolian conventional heating systems assumed as references, the proposed solar system is able to achieve significant reductions in terms primary energy consumption, the amount of burned coal, global carbon dioxide equivalent emissions as well as the operating costs (even if the expected return on investment could be unacceptable). In addition, this study revealed that the effects of dust deposition on evacuated tube 
heat pipe collectors on the overall energy, environmental and economic performances of the proposed heating plant are very relevant.

\section{Description of the Proposed Plant}

Figure 1 shows the scheme of the system configuration analyzed in this study.

The proposed plant basically consists of a sensible thermal energy storage (TES) with a single internal heat exchanger (IHE), solar field collectors (SFC) composed of four series-connected evacuated tube heat pipe panels thermally interacting with the tank through the internal heat exchanger, an auxiliary electric heater (EH) immersed in the storage, a low-pressure coal-burning stove (COS), four parallel-connected radiators (RAD), a solar circuit pump (SP), a radiators circuit pump (RP) and 7 thermostats $(\mathrm{T})$.

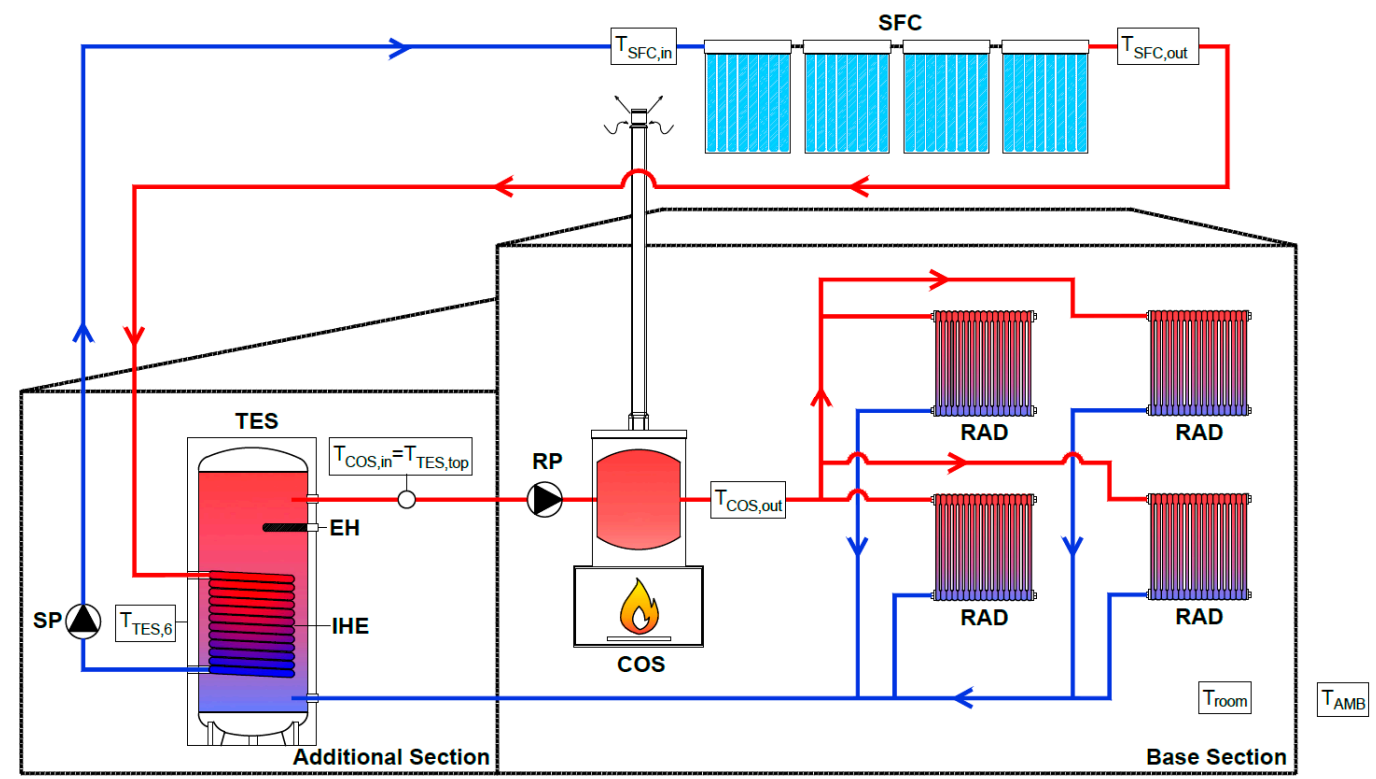

Figure 1. Schematic of the proposed plant.

Two different closed loops can be easily distinguished in Figure 1:

1. The solar thermal collectors circuit (including the solar thermal panels, the solar circuit pump and the heat exchanger immersed into the storage);

2. The space heating circuit (including the tank, the coal stove, the radiators circuit pump as well as the radiators).

The heat carrier fluid inside the solar thermal collectors circuit was a mixture (50\%/50\% by volume) of water and ethylene glycol $\left(c_{\mathrm{wg}}=3.26 \mathrm{~kJ} / \mathrm{kgK}, \rho_{\mathrm{wg}}=1069.0 \mathrm{~kg} / \mathrm{m}^{3}\right)$ in order to protect the system from the ill effects of freezing, while pure water $\left(c_{\mathrm{w}}=4.19 \mathrm{~kJ} / \mathrm{kgK}, \rho_{\mathrm{w}}=1000.0 \mathrm{~kg} / \mathrm{m}^{3}\right)$ flowed into the space heating loop.

The system aims to satisfy the space heating demand of a typical single-family detached house situated in the Chingeltei Ger district of Ulaanbaatar city in Mongolia (longitude: 106 $54^{\prime}$ East; latitude: $47^{\circ} 57^{\prime}$ North).

The heating purposes were covered by heating the pure water contained in the storage. The solar thermal collectors, the coal-burning stove as well as the electric heater co-operate in order to guarantee the desired thermal comfort. The solar energy captured by the solar thermal collectors is transferred, through the heat exchanger IHE, into the thermal energy storage. From the tank, if there is a heating demand, the solar energy is transferred into the distribution network and then to the end-users for space heating purposes through the group of radiators installed inside the house and supplied by the 
storage. The coal stove as well as the electric heater are used to supplement the space heating demand when the solar energy collected and stored in the tank cannot meet the thermal energy requirements.

All the electric requirements were satisfied with the electricity supplied by the central grid.

The system was simulated using the commercial TRNSYS software platform (version 17) [29] developed by the University of Wisconsin. It is one of the most popular advanced dynamic building energy simulation programs [30-32], with it modelling every physical piece of the thermodynamic equipment with a component (named Type) that is a FORTRAN source code model. In this study, the component modules were selected from the TRNSYS libraries and enhanced by the measurements, the manufacturer performance data or information available in current scientific literature. The simulations were performed with reference to the duration of the heating season with a two-minute simulation time-step.

The proposed plant has been modelled and operated according to the on-site characteristics of a solar hybrid heating system, indicated as the Triple System, experimentally investigated by the authors in a previous paper [33] while serving the same Mongolian detached house.

Figure 2 reports the screenshot of the project developed in the TRNSYS environment together with the main types used in this study. In the following sub-sections, the main characteristics of the system components together with the features of the TRNSYS Types as well as the control logics are described in detail.

\subsection{Description of the Detached House}

A typical single-family detached house, representative of the residential buildings currently in use in the Chingeltei Ger district of Ulaanbaatar in Mongolia, was investigated. The residence is composed of two main portions:

1. A base section, with a total floor area of $48 \mathrm{~m}^{2}$ and a volume of $144.0 \mathrm{~m}^{3}$;

2. An additional section, with a total floor area of $10 \mathrm{~m}^{2}$ and a volume of $22.1 \mathrm{~m}^{3}$.

Only the base section (where the low-pressure coal-burning stove as well as the radiators are located and installed) is heated, while the indoor temperature of the additional section is not controlled at any time. The additional section contains the thermal energy storage with the immersed electric heater and is separated by the base section through an internal wall.

Figure 3 shows the model of the house (obtained by using the software SketchUp Pro [34]) where both the base and additional sections are highlighted.

The main characteristics of the external walls of the house are indicated in Tables 1 and 2. In particular, the orientation, azimuth, surface slope, floor area, internal $\left(\mathrm{abs}_{\mathrm{i}, \text { wall }}\right)$ and external $\left(a_{\mathrm{b} s}\right.$,wall $)$ solar absorptances, internal $\left(\mathrm{h}_{\mathrm{i}, \text { wall }}\right)$ and external $\left(\mathrm{h}_{\mathrm{e}, \text { wall }}\right)$ convective heat transfer coefficients, wall thermal transmittance $\left(\mathrm{U}_{\text {wall }}\right)$, material, thickness (s) and thermal conductivity $(\lambda)$ of the layers were reported for each wall type. The values of $h_{i, w a l l}$ and $h_{e, \text { wall }}$ were derived from the European Standard EN ISO 6946:2007 [35], while the values of $\lambda$ were defined based on literature data.

The main characteristics of the windows of the base section are reported in Table 3. In particular, the orientation, azimuth, internal $\left(\mathrm{h}_{\mathrm{i}, \text { window }}\right)$ and external $\left(\mathrm{h}_{\mathrm{e}, \text { window }}\right)$ convective heat transfer coefficients, frame transmittance $U_{\text {frame, }}$ glazing transmittance $U_{\text {glazing, }}$, window type, spacing gas, glazing width, spacing width, frame area $\mathrm{A}_{\text {frame }}$ and window (glazing + frame) area $\mathrm{A}_{\text {window }}$ were specified. 


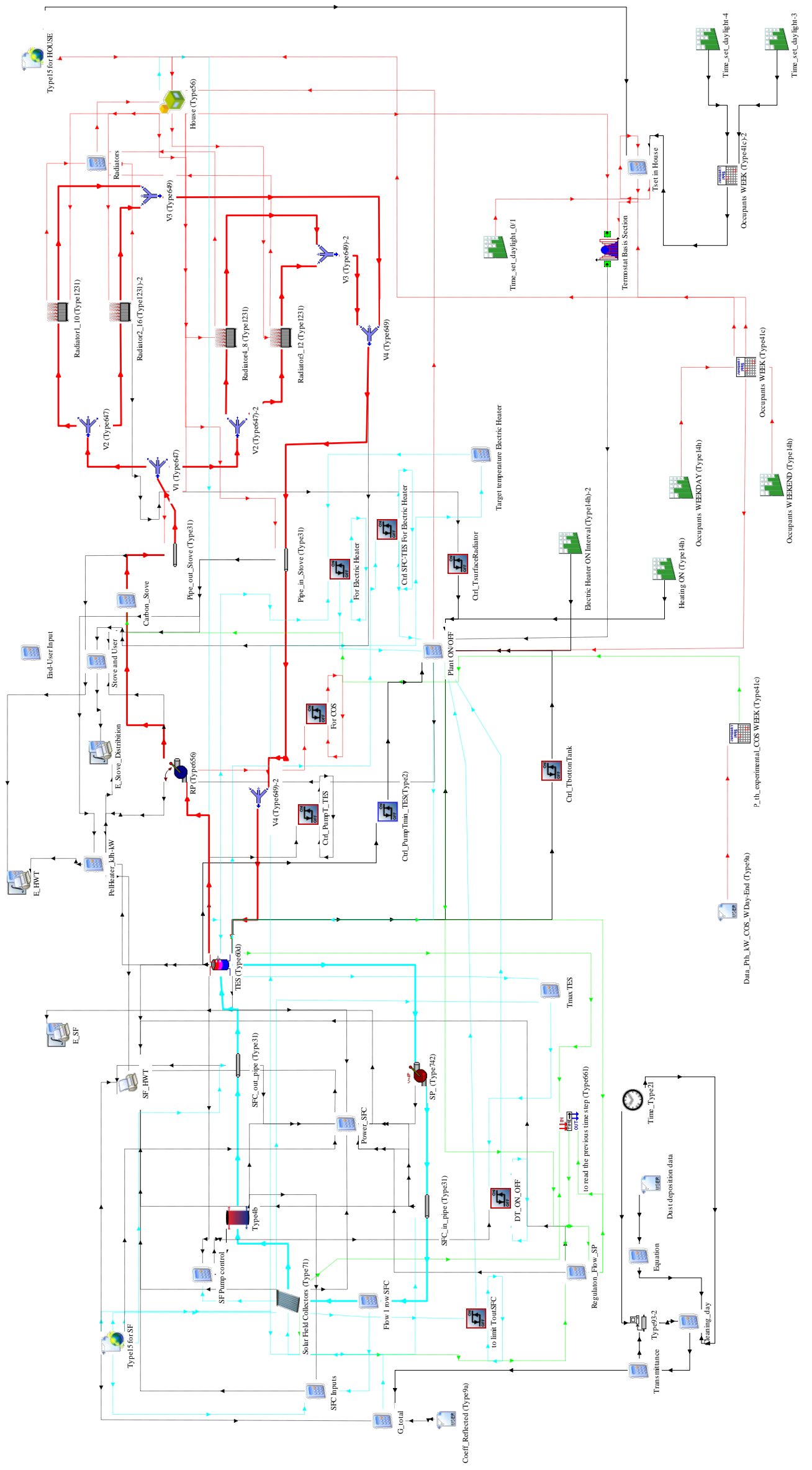

Figure 2. Scheme of the TRNSYS project. 

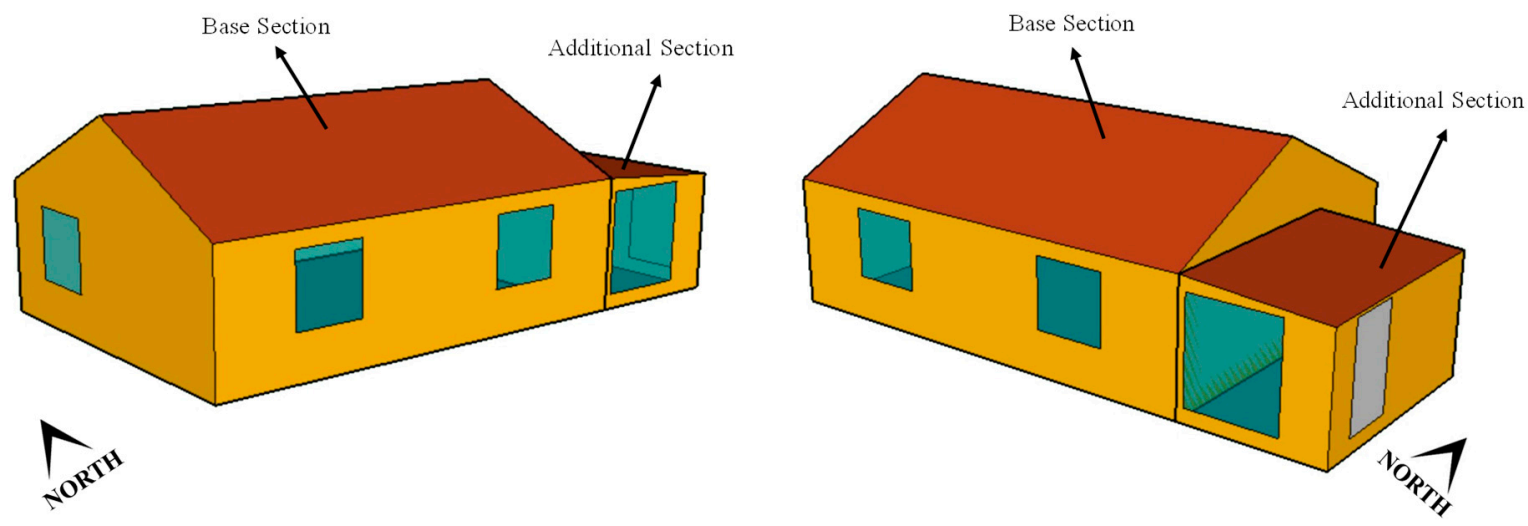

Figure 3. Architectural model of the Mongolian detached house.

Table 1. The materials of the walls of the house.

\begin{tabular}{|c|c|c|c|}
\hline & $\begin{array}{c}\text { Layer Material } \\
\text { (from Outside to Inside) }\end{array}$ & $\begin{array}{l}\text { Thickness } \\
\mathrm{s}(\mathrm{m})\end{array}$ & $\begin{array}{c}\text { Thermal } \\
\text { Conductivity } \\
\lambda(W / m K)\end{array}$ \\
\hline Floor of Base Section & Concrete & 0.300 & 1.160 \\
\hline Floor of Additional Section & Concrete & 0.150 & 1.160 \\
\hline \multirow{4}{*}{$\begin{array}{c}\text { Roof (Part } 1 \text { and Part 2) of Base } \\
\text { Section and } \\
\text { Roof of Additional Section }\end{array}$} & Timber block & 0.005 & 0.140 \\
\hline & Expanded polystyrene & 0.070 & 0.033 \\
\hline & Timber panel & 0.015 & 0.033 \\
\hline & Gypsum panel & 0.005 & 0.170 \\
\hline \multirow{4}{*}{ Vertical walls of Base Section } & Bricks & 0.100 & 0.810 \\
\hline & Glass wool & 0.030 & 0.037 \\
\hline & Timber block & 0.150 & 0.140 \\
\hline & Gypsum panel & 0.005 & 0.170 \\
\hline \multirow{2}{*}{$\begin{array}{l}\text { Vertical walls of Additional } \\
\text { Section }\end{array}$} & Bricks & 0.250 & 0.810 \\
\hline & Cement render & 0.010 & 0.350 \\
\hline \multirow{3}{*}{ Internal wall } & Sand and cement render & 0.010 & 0.350 \\
\hline & Timber block & 0.150 & 0.140 \\
\hline & Gypsum panel & 0.005 & 0.170 \\
\hline
\end{tabular}

Table 2. The characteristics of the walls of the house.

\begin{tabular}{|c|c|c|c|c|c|c|}
\hline \multicolumn{7}{|c|}{ BASE SECTION } \\
\hline Element Type & $\begin{array}{l}\text { Orientation/Azimuth } \\
\left(\left(^{\circ}\right)\right.\end{array}$ & $\begin{array}{c}\text { Surface Slope } \\
\left({ }^{\circ}\right)\end{array}$ & $\begin{array}{l}\text { Wall Area without } \\
\text { Windows } \\
\left(\mathrm{m}^{2}\right)\end{array}$ & $\underset{(-)}{\text { abs }_{i, w a l l} / \text { abs }_{e, w a l l}}$ & $\begin{array}{c}\mathbf{h}_{\mathbf{i}, \mathbf{w a l l}} / \mathbf{h}_{\mathrm{e}, \mathrm{wall}} \\
\left(\mathbf{W} / \mathbf{m}^{2} \mathbf{K}\right)\end{array}$ & $\begin{array}{c}U_{\text {wall }} \\
\left(W / m^{2} K\right)\end{array}$ \\
\hline Floor & Horizontal/- & 0 & 48.00 & $0.6 / 0.6$ & $0.70 / 20.00$ & 3.87 \\
\hline Roof (Part 1) & South/10 & 25 & 26.48 & $0.6 / 0.6$ & $5.00 / 20.00$ & 0.38 \\
\hline Roof (Part 2) & North/190 & 25 & 26.48 & $0.6 / 0.6$ & $5.00 / 20.00$ & 0.38 \\
\hline Front wall & South/10 & 90 & 15.40 & $0.6 / 0.6$ & $2.50 / 20.00$ & 0.49 \\
\hline Back wall & North/190 & 90 & 18.40 & $0.6 / 0.6$ & $2.50 / 20.00$ & 0.49 \\
\hline Left side wall & West/100 & 90 & 16.50 & $0.6 / 0.6$ & $2.50 / 20.00$ & 0.49 \\
\hline $\begin{array}{l}\text { Right side wall } \\
\text { (Part 1) }\end{array}$ & East/280 & 90 & 8.80 & $0.6 / 0.6$ & $2.50 / 20.00$ & 0.49 \\
\hline $\begin{array}{l}\text { Right side wall } \\
\text { (Part 2) }\end{array}$ & Internal wall & 90 & 6.30 & $0.6 / 0.6$ & $2.50 / 2.50$ & 0.89 \\
\hline \multicolumn{7}{|c|}{ ADDITIONAL SECTION } \\
\hline Floor & Horizontal/- & 0 & 10.00 & $0.6 / 0.6$ & $0.70 / 20.00$ & 7.73 \\
\hline Roof & East/280 & 4.35 & 10.03 & $0.6 / 0.6$ & $5.00 / 20.00$ & 0.38 \\
\hline Front wall & South/10 & 90 & 2.62 & $0.6 / 0.6$ & $2.50 / 20.00$ & 2.97 \\
\hline Back wall & North/190 & 90 & 5.52 & $0.6 / 0.6$ & $2.50 / 20.00$ & 2.97 \\
\hline Right side wall & East/280 & 90 & 6.65 & $0.6 / 0.6$ & $2.50 / 20.00$ & 2.97 \\
\hline Left side wall & Internal wall & 90 & 6.30 & $0.6 / 0.6$ & $2.50 / 2.50$ & 0.89 \\
\hline
\end{tabular}


The values of $h_{i, \text { window }}$ and $h_{e, \text { window }}$ were obtained from the European Standard EN ISO 10077-1:2006 [36], while the other parameters were defined according to manufacturer data.

The house is equipped with two doors. The first door is facing East and is characterized by a total area of $1.8 \mathrm{~m}^{2}$ with a thermal transmittance equal to $2.5 \mathrm{~W} / \mathrm{m}^{2} \mathrm{~K}$. The second door is placed internally between the base section and the additional section, with a total area of $2.9 \mathrm{~m}^{2}$ and a thermal transmittance equal to $2.5 \mathrm{~W} / \mathrm{m}^{2} \mathrm{~K}$.

The air change of infiltration induced by the wind and stack effect on the building envelope was assumed equal to $1.6 \mathrm{~h}^{-1}$ for the base section as an average of the reference values suggested by Tong et al. [37] for Mongolian residential applications.

Table 3. The characteristics of the windows of the house.

\begin{tabular}{|c|c|c|c|c|c|c|c|c|}
\hline \multicolumn{9}{|c|}{ BASIS SECTION } \\
\hline $\begin{array}{l}\text { Number of } \\
\text { Windows }\end{array}$ & $\begin{array}{c}\text { Orientation/Azimuth } \\
\left({ }^{\circ}\right)\end{array}$ & $\begin{array}{c}\mathrm{h}_{\mathrm{i}, \text { window }} / \mathrm{h}_{\mathrm{e}, \text { window }} \\
\left(\mathrm{W} / \mathrm{m}^{2} \mathrm{~K}\right)\end{array}$ & $\begin{array}{c}\mathrm{U}_{\text {frame }} / \mathrm{U}_{\text {glazing }} \\
\left(\mathrm{W} / \mathrm{m}^{2} \mathrm{~K}\right)\end{array}$ & $\begin{array}{l}\text { Window } \\
\text { Type }\end{array}$ & $\begin{array}{l}\text { Spacing } \\
\text { Gas }\end{array}$ & $\begin{array}{l}\text { Geometry } \\
(\mathrm{mm})\end{array}$ & $\begin{array}{c}\text { A }_{\text {frame }} \\
\left(\mathrm{m}^{2}\right)\end{array}$ & $\begin{array}{c}A_{\text {window }} \\
\left(\mathrm{m}^{2}\right)\end{array}$ \\
\hline 2 & South/10 & \multirow[t]{2}{*}{$2.50 / 20.00$} & \multirow[t]{2}{*}{$6.00 / 2.83$} & \multirow{2}{*}{$\begin{array}{l}\text { Double } \\
\text { glazing }\end{array}$} & \multirow[t]{2}{*}{ Air } & \multirow[t]{2}{*}{$4 / 16 / 4$} & \multirow{2}{*}{0.225} & \multirow{2}{*}{1.275} \\
\hline 1 & West/100 & & & & & & & \\
\hline \multicolumn{9}{|c|}{ ADDITIONAL SECTION } \\
\hline 1 & South/10 & $2.50 / 20.00$ & $6.00 / 2.83$ & $\begin{array}{l}\text { Double } \\
\text { glazing }\end{array}$ & Air & $4 / 16 / 4$ & 0.435 & 2.465 \\
\hline
\end{tabular}

Figure 4a shows the assumed occupancy profiles, i.e., the number of occupants of the base section as a function of the time during weekdays and weekends. The profiles reported in Figure 4a are based on the on-site survey activities performed with reference to typical residences in the Chingeltei Ger district of Ulaanbaatar.

Sensible heat coming from each occupant was assumed equal to $65 \mathrm{~W}$ according to the values recommended by the Standard ISO 7730 [38].

The room temperature inside the base section was set to be kept at the values indicated in Figure $4 \mathrm{~b}$ only from 7.00 a.m. to 11.00 p.m. (period with at least one occupant being inside the house in the case of the occupants are not sleeping) as a function of the outside temperature.

The duration of the heating period was assumed to be from 1 October up to 31 May.
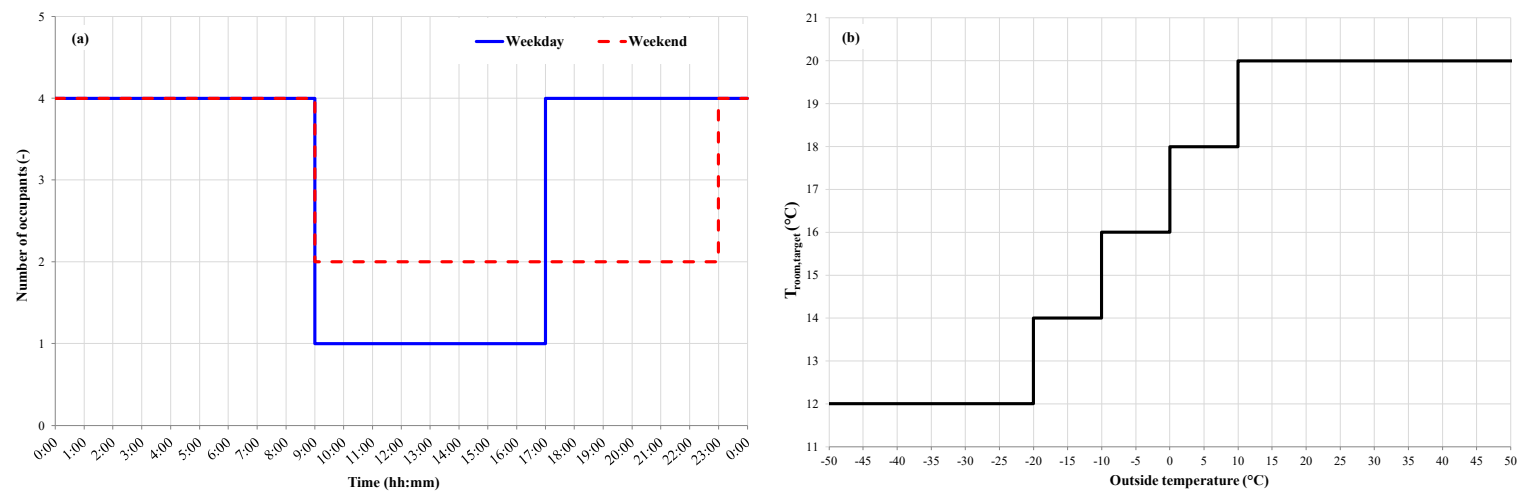

Figure 4. The daily profiles of the number of occupants as a function of the time (a) and the target room temperature as a function of the outside temperature $(\mathbf{b})$.

TRNSYS Type 56 (multi-zone building model) has been used to model and simulate the typical Mongolian detached house and related loads/gains. A specific EnergyPlus weather data file [39] was considered for modelling the weather data of Ulaanbaatar in terms of outdoor temperature and solar global irradiance (beam and diffuse). According to the above-mentioned weather data file, Figure 5 highlights how in Ulaanbaatar, the outside temperature is between $-32.7^{\circ} \mathrm{C}$ and $+26.7^{\circ} \mathrm{C}$, while the maximum global solar irradiance on the horizontal plane is approximately $950 \mathrm{~W} / \mathrm{m}^{2}$. 


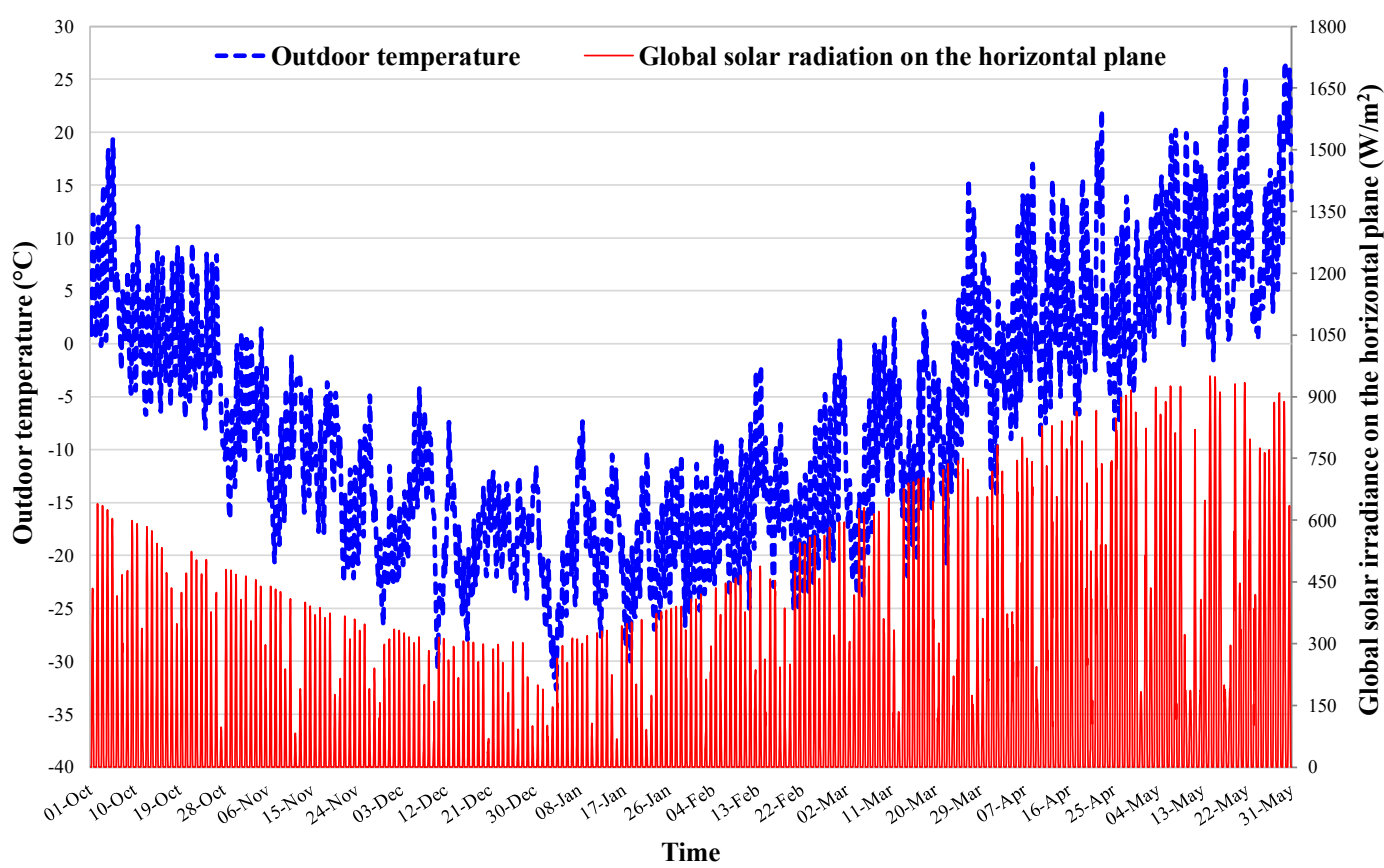

Figure 5. The outdoor temperature and global solar radiation on the horizontal plane during the heating season in Ulaanbaatar [39].

\subsection{Description of the Thermal Energy Storage}

A vertical cylindrical fluid-filled sensible energy storage (TES) equipped with an internal heat exchanger (IHE) allowing to store the solar energy recovered by the solar thermal collectors was adopted. The tank is characterized by one inlet and one outlet for the connection to the space heating circuit.

TRNSYS Type 534 was used to model and simulate the storage. This type is based on the assumption that the tanks can be divided into $\mathrm{N}$ fully-mixed equal sub-volumes. For each sub-volume, the transient state mass and energy balances are considered, making it possible to calculate the thermal stratification in the component. This instance further assumes that losses from each tank node are equal. In this paper, the storage was modelled with 10 isothermal temperature layers to better represent the thermal stratification, where the top layer was 1 and the bottom layer was 10 .

The main characteristics of the tank are reported in Table 4 .

Table 4. The main characteristics of the thermal energy storage.

\begin{tabular}{ll}
\hline Tank volume & $0.5 \mathrm{~m}^{3}$ \\
\hline Tank internal height & $1.695 \mathrm{~m}$ \\
\hline Height of flow inlet/outlet & $0.2 \mathrm{~m} / 1.6 \mathrm{~m}$ \\
\hline Tank loss coefficient & $2.34 \mathrm{~kJ} / \mathrm{hm}^{2} \mathrm{~K}$ \\
\hline Height of heat exchanger inlet & $1.4 \mathrm{~m}$ \\
\hline Height of heat exchanger outlet & $0.25 \mathrm{~m}$ \\
\hline Heat exchanger inside diameter & $0.021 \mathrm{~m}$ \\
\hline Heat exchanger outside diameter & $0.024 \mathrm{~m}$ \\
\hline Total surface area of heat exchanger & $1.3 \mathrm{~m}{ }^{2}$ \\
\hline Heat exchanger length & $17.5 \mathrm{~m}$ \\
\hline Heat exchanger material conductivity & $1436.4 \mathrm{~kJ} / \mathrm{hmK}$ \\
\hline
\end{tabular}




\subsection{Description of the Solar Thermal Collectors Circuit}

The solar circuit is composed of four series-connected evacuated tube heat pipe collectors (SFC) manufactured by the Chinese company Jiangsu Sunrain Solar Energy Co., Ltd. (model TZ58-1800-30) [40]. The installation angle between the collectors' surface and the horizontal plane is $60^{\circ}$ with an azimuth equal to $10^{\circ}$ (as in the experimental set-up). The total aperture area of the solar system is $11.36 \mathrm{~m}^{2}$.

TRNSYS Type 71 was used for modelling and simulating the performance of solar thermal collectors with their thermal efficiency $\eta_{\mathrm{SFC}}$ predicted by using the following formula:

$$
\eta_{\mathrm{SFC}}=\eta_{0}-\mathrm{a}_{1} \cdot\left(\mathrm{T}_{\mathrm{m}}-\mathrm{T}_{\mathrm{amb}}\right) / \mathrm{G}-\mathrm{a}_{2} \cdot\left(\mathrm{T}_{\mathrm{m}}-\mathrm{T}_{\mathrm{amb}}\right)^{2} / \mathrm{G}
$$

where $T_{a m b}$ is the external temperature, $G$ is the global solar irradiance and $T_{m}$ is the average temperature between the inlet $\left(\mathrm{T}_{\mathrm{SFC}, \text { in }}\right)$ and outlet $\left(\mathrm{T}_{\mathrm{SFC}, \text { out }}\right)$ of the solar thermal collectors. Based on the results of the experimental tests performed by the Institut für Thermodynamik und Wärmetechnik Universität Stuttgart [41] according to the European Standard EN 12975-2:2006 [42], the intercept efficiency $\eta_{0}$, the first order efficiency coefficient $a_{1}$ and the second order efficiency coefficient $a_{2}$ are, respectively, $0.592,1.889 \mathrm{~W} / \mathrm{m}^{2} \mathrm{~K}$ and $0.011 \mathrm{~W} / \mathrm{m}^{2} \mathrm{~K}^{2}$ with reference to the aperture area. The transverse and longitudinal incidence angle modifiers were also defined according to the information provided by the manufacturer. A fictional thermal energy storage is included into the TRNSYS project in order to take into account the thermal capacity of solar collectors. In particular, a fluid-filled fully-mixed sensible energy tank (modelled and simulated by means of TRNSYS Type $4 \mathrm{~b}$ ) with a volume of $216 \mathrm{~L}$ (loss coefficient equal to $1.889 \mathrm{~W} / \mathrm{m}^{2} \mathrm{~K}$ ) was considered according to the thermal capacity $\left(66.24 \mathrm{~kJ} / \mathrm{m}^{2} \mathrm{~K}\right.$ ) suggested by the manufacturer [40].

The experimental performance of the solar collector circuit was evaluated during October 2015 and April 2016 and then contrasted against the simulation results of the above-described model by the authors in a previous work [43]. The calibrated model exhibited a reasonable agreement when compared with the measured points with a percentage difference in terms of daily efficiency ranging between $-5.8 \%$ and $11.7 \%$. Therefore, it can be concluded that the TRNSYS model gives an accurate representation of the performance of solar thermal collectors during their operation under real conditions.

The dust deposition tests were conducted between October 2015 and May 2016 under the real environmental conditions in Ulaanbaatar [28]. The experiments highlighted that the daily glass tube transmittance during the ith day $\tau_{i}$ can be estimated by using the following formula:

$$
\tau_{i}=\tau_{i-1}-\left(A \cdot x_{i}+B \cdot y_{i}+C \cdot z_{1, i}+D \cdot z_{2, i}\right)
$$

where $\tau_{\mathrm{i}-1}$ is the daily glass tube transmittance during the (i-1)th day, $x_{i}$ is the daily average PM10 emissions $\left(\mathrm{mg} / \mathrm{m}^{3}\right)$, i.e., the emissions of particles with aerodynamic diameters less than or equal to $10 \mathrm{~m}$, during the ith day, $\mathrm{y}_{\mathrm{i}}$ is the daily average wind factor during the ith day, $\mathrm{z}_{1, \mathrm{i}}$ is the daily average rain rate $(\mathrm{mm})$ during the ith day and $\mathrm{z}_{2, \mathrm{i}}$ is the daily average snow rate $(\mathrm{mm})$ during the ith day; $\mathrm{A}, \mathrm{B}, \mathrm{C}$ and $\mathrm{D}$ are empirically-derived constants $\left(\mathrm{A}=1.67 \mathrm{~m}^{3} / \mathrm{mg}, \mathrm{B}=101, \mathrm{C}=-3.01 \mathrm{~mm}^{-1}\right.$ and $\mathrm{D}=-2.69 \mathrm{~mm}^{-1}$ ).

All the variables in Equation (2) can be directly measured except the daily average wind factor $\mathrm{y}_{\mathrm{i}}$. This parameter was calculated as follows:

$$
\mathrm{y}_{\mathrm{i}}=\frac{1}{\mathrm{~N}} \cdot \sum_{\mathrm{i}=1}^{\mathrm{N}}\left[1-\mathrm{e}^{[-\mathrm{L} \cdot(\mathrm{S}-\mathrm{Q})]}\right] \cdot \mathrm{w}
$$

where $N$ is the number of experimentally investigated glass tubes $(N=7), S$ is the wind speed $(\mathrm{m} / \mathrm{s}), \mathrm{w}$ is a factor indicating the wind direction $(\mathrm{w}=1$ if the wind comes from South, South-East or South-West, 
while $\mathrm{w}=0$ for the other wind directions), $\mathrm{L}$ and $\mathrm{Q}$ are empirically-derived constants $(\mathrm{L}=-0.007 \mathrm{~s} / \mathrm{m}$, $\mathrm{Q}=0.2 \mathrm{~m} / \mathrm{s})[28]$.

Equation (2) was validated against the measured data. According to the experimental measurements for clean tubes, the glass tube transmittance can assume a maximum value of 0.96 while the system is operating under clean conditions without the dust deposition.

\subsection{Description of the Solar Thermal Collectors Circuit}

The coal-burning stove (COS) is manufactured by the Mongolian company BURHANI GAL, Ltd (model: DULAAN-II) [44]. According to the catalogue data [44], the nominal thermal output is $6.0 \mathrm{~kW}_{\text {th }}$ with a thermal efficiency equal to $71 \%$. The thermal output of the stove was experimentally evaluated by the following formula:

$$
\begin{gathered}
\mathrm{P}_{\mathrm{COS}, \text { th }}=\dot{\mathrm{V}}_{\mathrm{w}} \cdot \rho_{\mathrm{W}} \cdot \mathrm{c}_{\mathrm{W}} \cdot\left(\mathrm{T}_{\mathrm{COS}, \text { out }}-\mathrm{T}_{\mathrm{COS}, \text { in }}\right) \\
=\mathrm{A} \cdot \mathrm{v}_{\mathrm{w}} \cdot \rho_{\mathrm{w}} \cdot \mathrm{c}_{\mathrm{w}} \cdot\left(\mathrm{T}_{\mathrm{COS}, \text { out }}-\mathrm{T}_{\mathrm{COS}, \text { in }}\right)
\end{gathered}
$$

where:

- $\quad \mathrm{P}_{\mathrm{COS}, \mathrm{th}}$ is the thermal power produced by the stove;

- $\quad \dot{V}_{\mathrm{w}}, \rho_{\mathrm{W}}, \mathrm{c}_{\mathrm{w}}$ and $\mathrm{v}_{\mathrm{w}}$ represent, respectively, the volumetric flow rate, the density, the specific heat and the velocity of the heat carrier fluid flowing inside the stove;

- A is the area of cross section of the tube inside which the heat carrier fluid is flowing;

- $\quad \mathrm{T}_{\mathrm{COS}, \text { out }}$ and $\mathrm{T}_{\mathrm{COS} \text {,in }}$ are, respectively, the temperature of the heat carrier fluid at the inlet and outlet of the stove.

A specific experiment was performed in order to obtain the thermal output of the stove $\mathrm{P}_{\mathrm{COS} \text {,th }}$ as a function of the time. In particular, the test was carried out by (i) fully charging the stove with the maximum allowed amount of stove before the start and (ii) then waiting for the complete consumption of the charged coal without recharging during the operation.

The values of $\rho_{\mathrm{w}}, \mathrm{c}_{\mathrm{w}}$ and A were assumed equal to $1000 \mathrm{~kg} / \mathrm{m}^{3}, 4.19 \mathrm{~kJ} / \mathrm{kgK}$ and $6.6 \mathrm{~cm}^{2}$, respectively. The values of $\mathrm{v}_{\mathrm{w}}$ were measured by means of a ultrasonic flowmeter (model TDS-100F) [45],

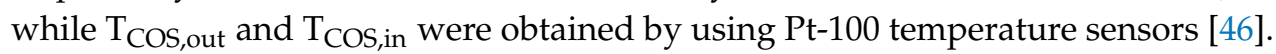

Figure 6 reports the values of $\mathrm{P}_{\mathrm{COS} \text {, th }}$ as a function of the time obtained from the experimental data. This figure highlights that the thermal output of the stove increases with the time up to a maximum value of approximately $6 \mathrm{~kW}$ (according to the manufacturer data [44]) and then decreases becoming equal to zero after approximately 6.5 hours of operation.

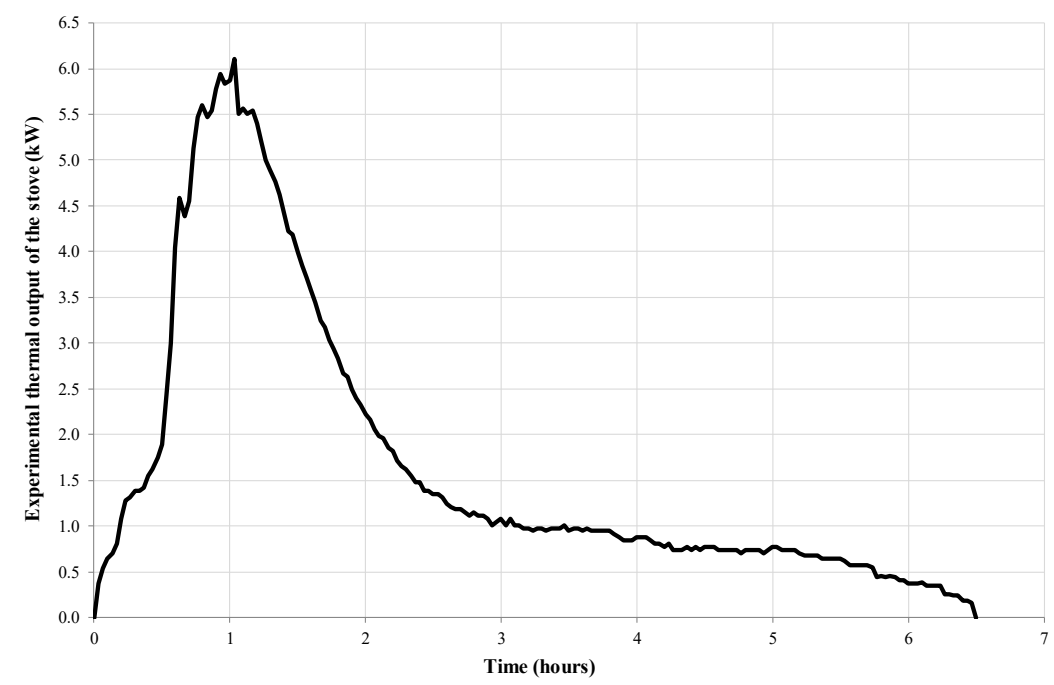

Figure 6. Experimental thermal output of the stove as a function of the time. 
The uncertainty associated with the measured values was calculated by using the procedure suggested by the Guide to the expression of uncertainty in measurement [47]. According to [47], the uncertainty $\mathrm{u}$ associated with a measurand $\mathrm{R}$ that depends upon a number of input quantities $R_{1}, \ldots, R_{N}$ can be performed by the following formula:

$$
\mathrm{u}(r)=\sqrt{\sum_{\mathrm{i}=1}^{\mathrm{N}}\left(\partial \mathrm{f} / \partial \mathrm{x}_{\mathrm{i}}\right)^{2} \cdot \mathrm{u}^{2}\left(\mathrm{x}_{\mathrm{i}}\right)}
$$

where $f$ is the functional relationship between $R$ and $R_{1}, \ldots, R_{N}$ and $r$ is an estimation of the measure and $R$ is obtained by substituting the measured values $r_{1}, \ldots, r_{N}$ of the parameters $R_{1}, \ldots, R_{N}$ in the Equation (5). As a consequence, the relative uncertainty of $\mathrm{P}_{\mathrm{COS} \text {, th }}$ can be calculated as follows by applying the propagation of uncertainties [48]:

$$
\mathrm{u}\left(\mathrm{P}_{\mathrm{COS}, \text { th }}\right) / \mathrm{P}_{\mathrm{COS}, \text { th }}=\sqrt{\begin{array}{l}
\mathrm{u}^{2}\left(\mathrm{v}_{\mathrm{w}}\right) / \mathrm{v}_{\mathrm{w}}^{2}+\mathrm{u}^{2}\left(\mathrm{~T}_{\mathrm{COS}, \text { out }}\right) /\left(\mathrm{T}_{\mathrm{COS}, \text { out }}-\mathrm{T}_{\mathrm{COS}, \text { in }}\right)^{2}+ \\
+\mathrm{u}^{2}\left(\mathrm{~T}_{\mathrm{COS}, \text { in }}\right) /\left(\mathrm{T}_{\mathrm{COS}, \text { out }}-\mathrm{T}_{\mathrm{COS}, \text { in }}\right)^{2}
\end{array}}
$$

According to the manufacturers data $[45,46]$, the uncertainty associated with the measurement of $\mathrm{v}_{\mathrm{W}}$ is equal to $1 \%$ of the reading, while the measurement uncertainty of $\mathrm{T}_{\mathrm{COS} \text {, out }}$ and $\mathrm{T}_{\mathrm{COS} \text {, in }}$ is $0.3^{\circ} \mathrm{C}$. Therefore, the relative uncertainty of $\mathrm{P}_{\mathrm{COS} \text {,th }}$ ranges from $2.5 \%$ up to $26.5 \%$, with an average value equal to $12.9 \%$.

The stove was simulated via TRNSYS Type 9a by assuming a simulated thermal output of the stove exactly equal to the experimental profile reported in Figure 6 where the stove is fully charged at the starting point and it is not recharged during the operation.

The heating rate of the auxiliary electric heater $(\mathrm{EH})$ was set to $3.0 \mathrm{~kW}_{\mathrm{el}}$ by assuming that the consumed power was entirely converted into its thermal output. The electric resistance was positioned into the storage with a height above the bottom of $0.4 \mathrm{~m}$.

\subsection{Description of Radiators}

The four parallel-connected aluminum radiators (RAD) commercialized by the Italian company Fondital S.p.A. (model: Calidor Super Aleternum) [49] were installed inside the base section of the house as terminal hydraulic units. They were supplied by the thermal energy storage and supplemented by the coal-burning stove.

The radiators were modelled by using TRNSYS Type 1231. In particular, each single radiator is composed of 24 sections and it is characterized by a design capacity of $5434.6 \mathrm{~kJ} / \mathrm{h}$ with a design delta-T exponent of 1.3268 (in the case of design surface temperature and design air temperature equal to $50^{\circ} \mathrm{C}$ and $20^{\circ} \mathrm{C}$, respectively).

\subsection{Description of Auxiliaries}

A single pair of supply and return pipes was used for both the solar thermal collector circuit as well as the space heating circuit.

The pipe connecting the thermal energy storage with the inlet of the solar thermal collector circuit has a length of $15 \mathrm{~m}$ and an inner diameter of $0.017 \mathrm{~m}$, while the pipe from the outlet of the solar field to the tank is characterized by a length of $11 \mathrm{~m}$ with an inner diameter of $0.017 \mathrm{~m}$. Both pipes of the space heating circuit were modelled with a length of $30 \mathrm{~m}$ and an inner diameter of $0.025 \mathrm{~m}$.

TRNSYS Type 31 was used to model and simulate the pipes and calculate the related heat losses by considering a loss coefficient equal to $7.64 \mathrm{~kJ} /\left(\mathrm{hm}^{2} \mathrm{~K}\right)$.

The solar circuit pump was modelled as a variable speed pump (with a volumetric flow rate ranging between 2.0 and $6.6 \mathrm{l} / \mathrm{min} /$ collector) by using TRNSYS Type 742, while TRNSYS Type 656 was used for modelling and simulating the single-speed pump (with a mass flow rate equal to $540 \mathrm{~kg} / \mathrm{h}$ ) 
of the space heating circuit. The electricity consumption of both pumps is assumed equal to $93 \mathrm{~W}$ during operation.

\subsection{Description of Control Logics}

The operation strategies used in this study for the proposed system are summarized in Tables 5-7. The logics controlling the operation of main components are defined according to the usual operation in Mongolian residential applications.

Table 5. The main control algorithms and strategies of the proposed system (PS).

\begin{tabular}{ccc}
\hline Component & ON & OFF \\
\hline $\begin{array}{c}\text { Solar circuit pump } \\
\text { (during normal operation) }\end{array}$ & $\Delta \mathrm{T}_{\mathrm{ON}}=\left(\begin{array}{c}\left.\mathrm{T}_{\mathrm{SFC}, \text { out }}-\mathrm{T}_{\mathrm{TES}, 6}\right) \geq \\
8{ }^{\circ} \mathrm{C}\end{array}\right.$ & $\begin{array}{c}\Delta \mathrm{T}_{\mathrm{ON}}=\left(\mathrm{T}_{\mathrm{SFC}, \text { out }}-\mathrm{T}_{\mathrm{TES}, 6}\right)< \\
4{ }^{\circ} \mathrm{C}\end{array}$ \\
\hline $\begin{array}{c}\text { Radiators pump from } 7.00 \text { a.m. to } \\
\text { 11.00 p.m. }\end{array}$ & $\mathrm{T}_{\text {room }} \leq \mathrm{T}_{\text {room,target }}-1.5^{\circ} \mathrm{C}$ & $\mathrm{T}_{\text {room }} \geq \mathrm{T}_{\text {room,target }}+1.5^{\circ} \mathrm{C}$ \\
\hline $\begin{array}{c}\text { Electric heater from } 4.30 \text { a.m. to } \\
\text { 11.00 p.m. }\end{array}$ & $\mathrm{T}_{\mathrm{TES} \text {,top }} \leq \mathrm{T}_{\mathrm{TES}, \text { top,target }}-5^{\circ} \mathrm{C}$ & $\mathrm{T}_{\mathrm{TES}, \text { top }} \geq \mathrm{T}_{\mathrm{TES}, \text { top,target }}$ \\
\hline
\end{tabular}

Table 6. Set-point temperature at the top of the thermal energy storage for the operation of the proposed system.

\begin{tabular}{|c|c|c|c|c|}
\hline & \multicolumn{2}{|c|}{ Activation State } & \multicolumn{2}{|c|}{$\mathrm{T}_{\mathrm{TES}, \text { top,target }}\left({ }^{\circ} \mathrm{C}\right)$} \\
\hline & Solar Circuit Pump & Radiators Pump & 4.30 a.m. -7.00 a.m. & 7.00 a.m. -11.00 p.m. \\
\hline $\mathrm{T}_{\mathrm{amb}}>-10^{\circ} \mathrm{C}$ & OFF or ON & OFF or ON & 35 & 35 \\
\hline \multirow{3}{*}{$\mathrm{T}_{\mathrm{amb}} \leq-10^{\circ} \mathrm{C}$} & \multirow{2}{*}{ OFF } & ON & 55 & 55 \\
\hline & & OFF & 55 & 35 \\
\hline & ON & $\begin{array}{l}\text { ON } \\
\text { OFF }\end{array}$ & 55 & 35 \\
\hline
\end{tabular}

The control strategies of the solar circuit pump are defined according to the one suggested by the manufacturer of the solar thermal collectors [40]. In particular, during normal operation (i.e., temperature at the outlet of the solar thermal collectors $\mathrm{T}_{\mathrm{SFC} \text {,out }}<130{ }^{\circ} \mathrm{C}$ and temperature at top of thermal energy storage $\mathrm{T}_{\mathrm{TES} \text {,top }}<80^{\circ} \mathrm{C}$ ), the activation of the solar circuit pump is based on the switch-on temperature difference $\Delta \mathrm{T}_{\mathrm{ON}}$ equal to the difference between the current values of the temperature at the outlet of the solar field $\mathrm{T}_{\mathrm{SFC} \text {,out }}$ and the temperature at node 6 of thermal energy storage $\mathrm{T}_{\mathrm{TES}, 6}$. In particular, the solar circulation pump is triggered and the volumetric flow rate reaches its minimum value $(2.0 \mathrm{l} / \mathrm{min} /$ collector $)$ in the case of $\Delta \mathrm{T}_{\mathrm{ON}} \geq 8^{\circ} \mathrm{C}$. Then, the volumetric flow rate of the solar circuit pump is adjusted between $2.0 \mathrm{l} / \mathrm{min} /$ collector and $6.6 \mathrm{l} / \mathrm{min} /$ collector depending on the standard temperature difference (STD) between the inlet and outlet of the internal heat exchanger (IHE) immersed in the thermal energy storage. When the STD becomes higher than $8^{\circ} \mathrm{C}$, the speed of the pump is increased by $0.2 \mathrm{l} / \mathrm{min}$ automatically (under the precondition that the maximum flow rate is not exceeded) trying to maintain $\mathrm{STD}=8^{\circ} \mathrm{C}$. On the other hand, the volumetric flow rate is reduced by $0.2 \mathrm{l} / \mathrm{min}$ automatically (under the precondition that the minimum flow rate is not exceeded) if STD becomes lower than $8{ }^{\circ} \mathrm{C}$ (but larger than $4^{\circ} \mathrm{C}$ ). The solar circulation pump is switched off when $\Delta \mathrm{T}_{\mathrm{ON}}$ becomes lower than $4{ }^{\circ} \mathrm{C}$.

In the case of the temperature at the outlet of solar collectors rising up to $130{ }^{\circ} \mathrm{C}$, the solar circulation pump is stopped. Then, the pump restarts when the temperature of the fluid exiting the solar field drops to $120^{\circ} \mathrm{C}$. When the tank temperature at the top $\mathrm{T}_{\mathrm{TES} \text {,top }}$ becomes equal to $80^{\circ} \mathrm{C}$, the solar circulation pump is stopped. However, when the temperature at the collectors outlet rises up to $110^{\circ} \mathrm{C}$, the solar circulation pump is triggered again even if the tank temperature at the top is already at its maximum value $\left(80^{\circ} \mathrm{C}\right)$ and the pump works until $\mathrm{T}_{\mathrm{TES} \text {,top }}$ increases up to its emergency stop temperature of $95^{\circ} \mathrm{C}$. 
The heat carrier fluid (pure water) can flow through the radiators (with a constant mass flow rate, defined according to the manufacturer data [49], equal to $540 \mathrm{~kg} / \mathrm{h}$ ) only from $7.00 \mathrm{a}$.m. up to $11.00 \mathrm{p} . \mathrm{m}$. (the radiators pump is switched off out of this period) in the cases when there is a call for heat triggered by a thermostat installed inside the house. The room temperature is set to be kept at the values indicated in Figure $4 \mathrm{~b}$, with a dead band of $3.0^{\circ} \mathrm{C}$. This means that, as indicate in Table 5, when the room temperature $\mathrm{T}_{\text {room }}$ is $1.5^{\circ} \mathrm{C}$ lower than the target room temperature $\mathrm{T}_{\text {room,target, }}$, the thermostat calls for heat from the tank. The call for a heat signal is disabled when $\mathrm{T}_{\text {room }}$ becomes $1.5^{\circ} \mathrm{C}$ higher than $\mathrm{T}_{\text {room,target }}$.

The electric heater can be operated only from 4.30 a.m. up to 11.00 p.m. (it is not used out of this period) in order to cooperate with the solar field and the stove in maintaining the set-point temperature at the top of the thermal energy storage $\mathrm{T}_{\mathrm{TES} \text {,top,target }}$. The values of $\mathrm{T}_{\mathrm{TES} \text {,top,target }}$ depend on (i) the outdoor temperature $\mathrm{T}_{\mathrm{amb}}$, activation state of both (ii) solar circuit pump and (iii) radiators pump, as well as (iv) the period of the day according to the conditions indicated in Table 6. As reported in Table 5, the electric heater is activated in the case of the actual temperature at the top of the storage $\mathrm{T}_{\mathrm{TES} \text {,top }}$ being $5{ }^{\circ} \mathrm{C}$ lower than $\mathrm{T}_{\mathrm{TES} \text {,top,target }}$ and it continues to operate trying to achieve the set-point temperature at the top of the thermal energy storage while providing its rated thermal output of $3.0 \mathrm{~kW}$.

The $6 \mathrm{~kW}_{\text {th }}$ coal-burning stove is fully charged and activated at 7.00 a.m. every-day. Then it is recharged (in order to replace the amount of consumed coal) at the following times (the number of charging points is greater when the degradation effects of dust deposition on solar collectors have to be balanced):

- $\quad 7.00$ a.m., 4.00 p.m., 8.00 p.m. (in the case of the soiling effects are neglected);

- 7.00 a.m., 10.00 a.m., 4.00 p.m., 8.00 p.m. (in the case of the soiling effects are taken into account).

Figure $7 \mathrm{a}, \mathrm{b}$ report the thermal power produced by the coal-burning stove (with and without the effects of dust deposition, respectively) assumed in the simulations during the daily operation according to both the experimental trend reported in Figure 6 as well as the above-mentioned charging points. The heat produced by the stove and reported in Figure $7 \mathrm{a}, \mathrm{b}$ is delivered to the space heating circuit only when the radiators pump is activated (Tables 5 and 6), but the coal is burning continuously even if the heat carrier fluid is not flowing through the radiators. Therefore, the coal consumption is taken into account also when the heating circuit is not operating (according to the actual operation of the stoves in Mongolia).
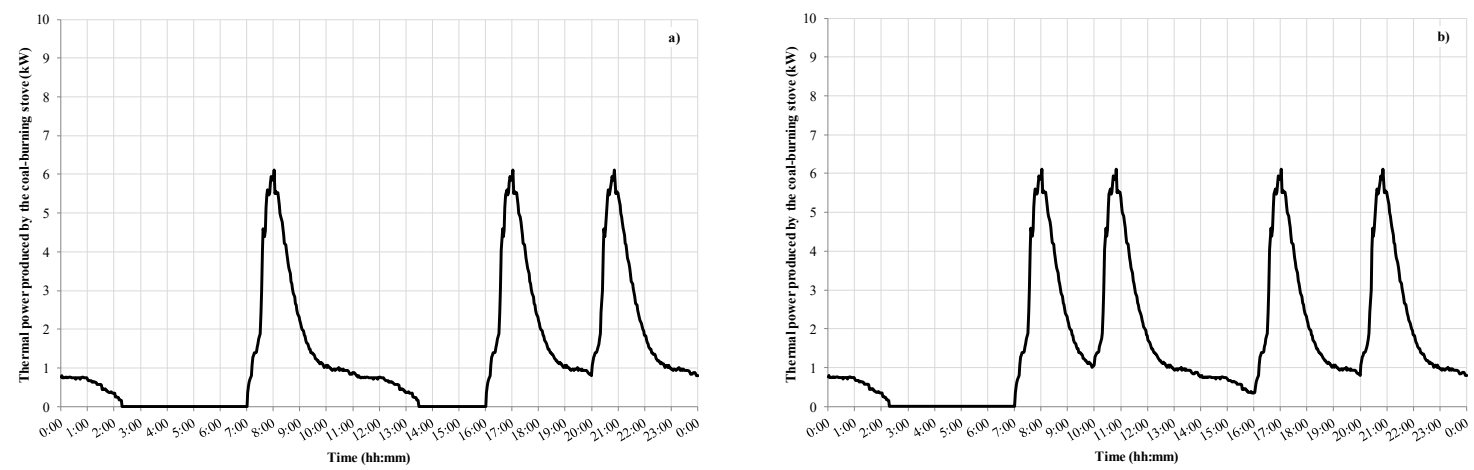

Figure 7. Daily thermal power produced by the stove for (a) the proposed system without dust deposition and (b) the proposed system with dust deposition.

The on/off differential controllers were modelled in TRNSYS by using Type 2 in order to generate an on signal when the watched value fell below the user-specified set-point by a certain amount and then, the systems were turned off when the watched variable approached the set-point within a specified amount.

The parameters affecting the control logics of the proposed system were calibrated based on an iterative approach in order to (i) take into account the usual operation of heating systems in the Ger 
districts of Ulaanbaatar, (ii) maintain the house indoor air temperature within the desired temperature ranges during $95 \%$ of the entire simulation period, as well as (iii) minimize both primary energy consumption and carbon dioxide equivalent emissions.

\section{Reference Systems}

The performance of the proposed plant (PS), described in Figure 1, are compared from the energy, environmental and economic points of view with those associated with three different conventional heating systems assumed as references while serving the same detached house.

The plants assumed as references were derived from the proposed system by removing one or more components.

The first conventional heating system (CS1) is the most representative heating system in the Ger districts of Ulaanbaatar taking into account that $98 \%$ of the total households use only raw coal to satisfy the heating demand [1]. This system only consists of a low-pressure coal-burning stove, with a nominal thermal output of $9.0 \mathrm{~kW}_{\mathrm{th}}$, supplying the radiators installed inside the house. The thermal output of the $9.0 \mathrm{~kW}_{\text {th }}$ stove was theoretically derived from that one reported in Figure 6 with a scaling factor equal to 1.5. The second reference system (CS2) was obtained from the proposed system by removing the entire solar circuit (solar collectors, solar circuit pump, heat exchanger immersed in the storage and pipes) without any other modifications. Therefore, in this case, the heating demand is satisfied by both the coal-burning stove as well as the electric heater installed inside the tank.

The third reference system (CS3) was composed of a thermal energy storage with an immersed electric heater (with a nominal electric output of $9.0 \mathrm{~kW}$ ) supplying the radiators. Even if a fully electric heating system with the entire elimination of the coal does not represent a realistic option for Mongolian applications in the current situation due to the reasons highlighted in Section 1. Introduction of this paper, the proposed system was also compared with CS3 in order to explore and assess the theoretical benefits/drawbacks associated with a potential future scenario.

Figure 8a-c report the schematics of the conventional heating systems CS1, CS2 and CS3, respectively. The main control algorithms and strategies of the conventional heating systems CS1, CS2 and CS3 are described in Table 7.

Table 7. The main control algorithms and strategies of the conventional heating systems CS1, CS2 and CS3.

\begin{tabular}{|c|c|c|c|c|}
\hline & \multirow{2}{*}{$\begin{array}{c}\text { Charging Times of } \\
\text { the Stove } \\
\text { (hh:mm) }\end{array}$} & & \multicolumn{2}{|c|}{ Component } \\
\hline & & & Radiators Pump & Electric Heater \\
\hline \multirow{9}{*}{$\begin{array}{l}\text { Conventional } \\
\text { system CS1 }\end{array}$} & \multirow{9}{*}{$\begin{array}{c}7: 00 \\
9: 00 \\
10: 30 \\
12: 00 \\
13: 30 \\
15: 00 \\
16: 30 \\
18: 00 \\
19: 30 \\
21: 00 \\
22: 30\end{array}$} & & & \\
\hline & & & & \\
\hline & & & & \\
\hline & & $\mathrm{ON}$ & $\mathrm{T}_{\text {room }} \leq \mathrm{T}_{\text {room,target }}-$ & - \\
\hline & & ON & $1.5^{\circ} \mathrm{C}$ & - \\
\hline & & & & \\
\hline & & & & \\
\hline & & & & \\
\hline & & OFF & $\begin{array}{c}\mathrm{T}_{\text {room }} \geq \mathrm{T}_{\text {room,target }}+ \\
1.5^{\circ} \mathrm{C}\end{array}$ & - \\
\hline \multirow{3}{*}{$\begin{array}{l}\text { Conventional } \\
\text { system CS2 }\end{array}$} & \multirow{3}{*}{$\begin{array}{c}7: 00 \\
10: 30 \\
14: 00 \\
17: 30 \\
21: 00\end{array}$} & ON & $\begin{array}{c}\mathrm{T}_{\text {room }} \leq \mathrm{T}_{\text {room,target }}- \\
1.5^{\circ} \mathrm{C}\end{array}$ & $\begin{array}{c}\mathrm{T}_{\mathrm{TES}, \text { top }} \leq 45^{\circ} \mathrm{C} \\
\text { AND }\end{array}$ \\
\hline & & & & Radiators pump ON \\
\hline & & OFF & $\begin{array}{c}\mathrm{T}_{\text {room }} \geq \mathrm{T}_{\text {room,target }}+ \\
1.5^{\circ} \mathrm{C}\end{array}$ & $\begin{array}{c}\mathrm{T}_{\mathrm{TES}, \text { top }} \geq 55^{\circ} \mathrm{C} \\
\text { OR } \\
\text { Radiators pump OFF }\end{array}$ \\
\hline \multirow[t]{2}{*}{$\begin{array}{l}\text { Conventional } \\
\text { system CS3 }\end{array}$} & \multirow[t]{2}{*}{-} & ON & $\begin{array}{c}\mathrm{T}_{\text {room }} \leq \mathrm{T}_{\text {room,target }}- \\
1.5^{\circ} \mathrm{C}\end{array}$ & $\mathrm{T}_{\mathrm{TES}, \text { top }} \leq 40^{\circ} \mathrm{C}$ \\
\hline & & OFF & $\begin{array}{c}\mathrm{T}_{\text {room }} \geq \mathrm{T}_{\text {room,target }}+ \\
1.5^{\circ} \mathrm{C}\end{array}$ & $\mathrm{T}_{\mathrm{TES}, \text { top }} \geq 55^{\circ} \mathrm{C}$ \\
\hline
\end{tabular}



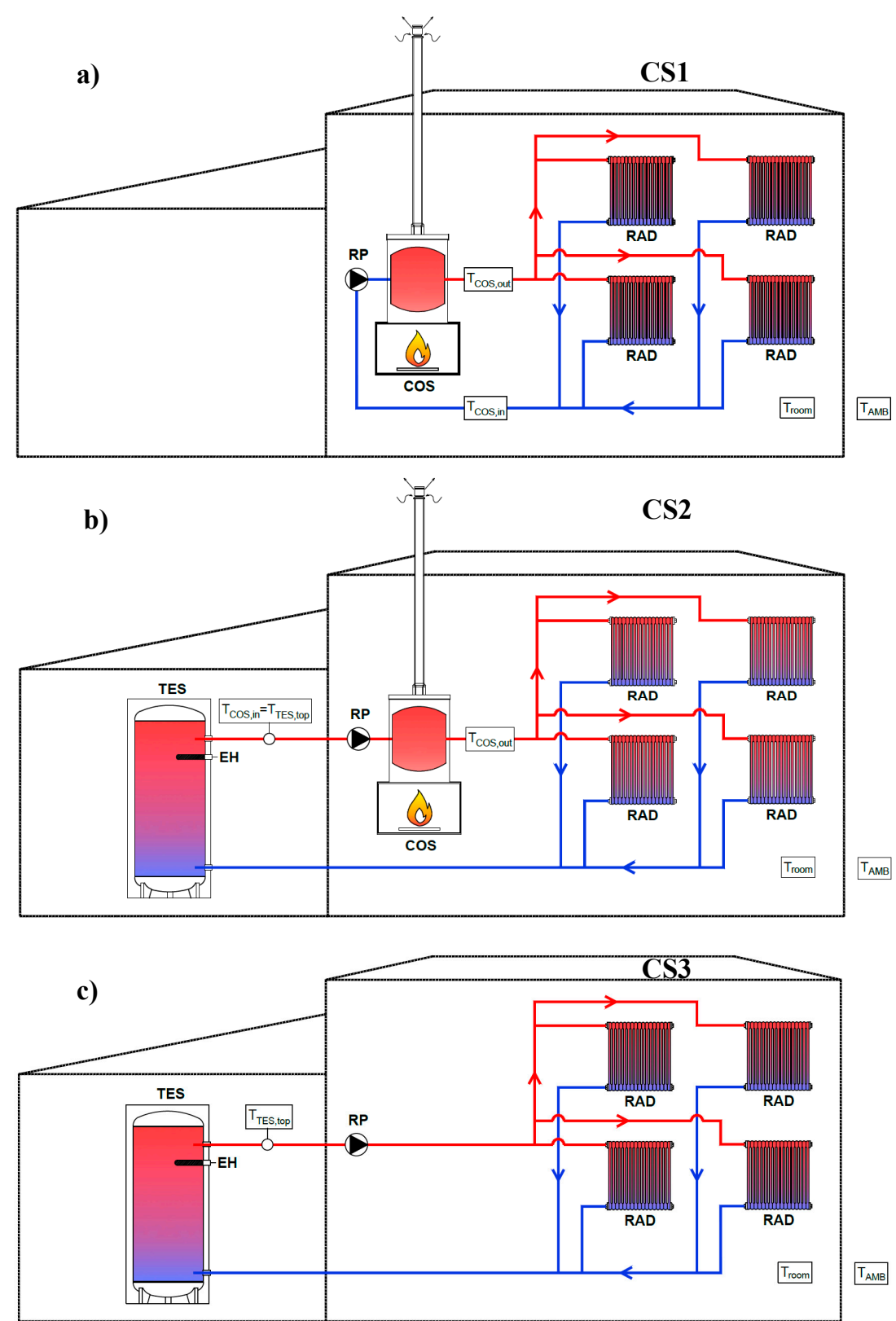

Figure 8. Schematics of the conventional heating system CS1 (a), the conventional heating system CS2 (b) and the conventional heating system CS3 (c).

The parameters affecting the control logics of the conventional heating systems were calibrated based on an iterative approach in order to (i) take into account the usual operation of heating systems in the Ger districts of Ulaanbaatar as well as (ii) maintain the house indoor air temperature within the desired temperature ranges during $95 \%$ of the entire simulation period.

Figure 9a,b report the thermal power produced by the coal-burning stove (for CS1 and CS2, respectively) assumed in the simulations during the daily operation according to the experimental trend reported in Figure 6 as well as the charging points indicated in Table 7. As assumed for the proposed system, the heat produced by the stove and reported in Figure 9a,b was delivered to the space heating circuit only when the radiators pump was activated (Table 7), but the coal was burning continuously even if the heat carrier fluid was not flowing through the radiators. Therefore, the coal consumption for both CS1 and CS2 is taken into account also when the heating circuit is not. 

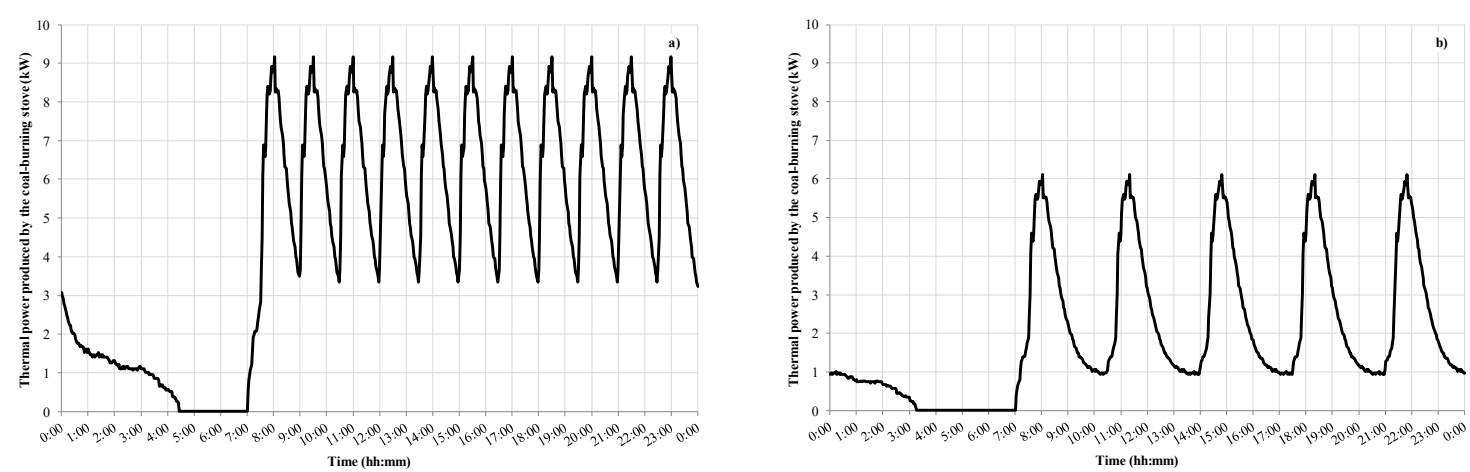

Figure 9. Daily thermal power produced by the stove for (a) the conventional heating system CS1 and (b) the conventional heating system CS2.

\section{Methods of Analysis}

The comparison between the proposed Triple System and the reference heating systems was performed in terms of primary energy consumption, the amount of coal that is burned, carbon dioxide equivalent emissions and operating costs by adopting the approaches/parameters described in the following sub-sections.

\subsection{Energy Analysis}

The energy comparison was carried out by calculating the index named primary energy saving (PES):

$$
\mathrm{PES}=\left(\mathrm{E}_{\mathrm{p}}^{\mathrm{CS}}-\mathrm{E}_{\mathrm{p}}^{\mathrm{PS}}\right) / \mathrm{E}_{\mathrm{p}}^{\mathrm{CS}}
$$

where $E_{p}^{P S}$ is the primary energy consumed by the proposed system and $E_{p}^{C S}$ is the primary energy associated with the conventional system. The terms in Equation (7) are defined as follows:

$$
\begin{gathered}
\mathrm{E}_{\mathrm{p}}^{\mathrm{PS}}=\mathrm{E}_{\mathrm{COS}, \mathrm{p}}+\mathrm{E}_{\mathrm{EH}, \mathrm{p}}+\mathrm{E}_{\mathrm{SP}, \mathrm{p}}+\mathrm{E}_{\mathrm{RP}, \mathrm{p}} \\
=\mathrm{E}_{\mathrm{COS}, \mathrm{th}} / \eta_{\mathrm{COS}}+\mathrm{E}_{\mathrm{EH}, \mathrm{el}} / \eta_{\mathrm{PP}}+\mathrm{E}_{\mathrm{SP}, \mathrm{el}} / \eta_{\mathrm{PP}}+\mathrm{E}_{\mathrm{RP}, \mathrm{el}} / \eta_{\mathrm{PP}} \\
\quad \mathrm{E}_{\mathrm{p}}^{\mathrm{CS} 1}=\mathrm{E}_{\mathrm{COS}, \mathrm{p}}+\mathrm{E}_{\mathrm{RP}, \mathrm{p}} \\
=\mathrm{E}_{\mathrm{COS}, \mathrm{th}} / \eta_{\mathrm{COS}}+\mathrm{E}_{\mathrm{RP}, \mathrm{el}} / \eta_{\mathrm{PP}} \\
\mathrm{E}_{\mathrm{p}}^{\mathrm{CS} 2}=\mathrm{E}_{\mathrm{COS}, \mathrm{p}}+\mathrm{E}_{\mathrm{EH}, \mathrm{p}}+\mathrm{E}_{\mathrm{RP}, \mathrm{p}} \\
=\mathrm{E}_{\mathrm{COS}, \mathrm{th}} / \eta_{\mathrm{COS}}+\mathrm{E}_{\mathrm{EH}, \mathrm{el}} / \eta_{\mathrm{PP}}+\mathrm{E}_{\mathrm{RP}, \mathrm{el}} / \eta_{\mathrm{PP}} \\
\mathrm{E}_{\mathrm{p}}^{\mathrm{CS} 3}=\mathrm{E}_{\mathrm{EH}, \mathrm{p}}+\mathrm{E}_{\mathrm{RP}, \mathrm{p}} \\
=\mathrm{E}_{\mathrm{EH}, \mathrm{el}} / \eta_{\mathrm{PP}}+\mathrm{E}_{\mathrm{RP}, \mathrm{el}} / \eta_{\mathrm{PP}}
\end{gathered}
$$

where $\mathrm{E}_{\mathrm{COS}, \mathrm{p}}, \mathrm{E}_{\mathrm{EH}, \mathrm{p}}, \mathrm{E}_{\mathrm{SP}, \mathrm{p}}, \mathrm{E}_{\mathrm{RP}, \mathrm{p}}$ represent the primary energy consumed by the coal-burning stove (relating to the periods during which the coal is burning, even if the thermal output of the stove is not delivered to the space heating circuit), the electric heater, the solar circuit pump and the radiators circuit pump, respectively. $\mathrm{E}_{\mathrm{COS}, \text { th }}$ is the total thermal energy produced by the coal-burning stove (relating to the periods during which the coal is burning, even if the thermal output of the stove is not delivered to the space heating circuit). $\mathrm{E}_{\mathrm{EH}, \mathrm{el}}, \mathrm{E}_{\mathrm{SP}, \mathrm{el}}, \mathrm{E}_{\mathrm{RP}, \mathrm{el}}$ indicate the electric energy consumed by the electric heater, the solar circuit pump and the radiators circuit pump, respectively. Further, $\eta_{\operatorname{COS}}$ is the thermal efficiency of coal-burning stove (assumed equal to 0.71 according to the manufacturer data [44]) and $\eta_{\mathrm{PP}}$ is the power plant average efficiency in Mongolia, including transmission losses (assumed equal to 33\% [50]). 


\subsection{Environmental Analysis}

The assessment of the environmental impact was performed in terms of both the amount of coal that is burned as well as carbon dioxide equivalent emissions.

The amount of coal used by the stove included in the proposed and conventional systems CS1 and CS2 (the conventional system CS3 does not use the stove) was calculated as follows:

$$
\mathrm{m}_{\mathrm{coal}}=\mathrm{E}_{\mathrm{COS}, \mathrm{p}} / \mathrm{LHV}_{\mathrm{coal}}
$$

where $\mathrm{LHV}_{\text {coal }}$ is the lower heating value of coal (assumed equal to $14630 \mathrm{~kJ} / \mathrm{kg}_{\text {coal }}$ according to the Mongolian scenario [51]).

The calculation of the carbon dioxide equivalent emissions has been performed in this study through an energy output-based emission factor approach [52]. According to this approach, the mass $\mathrm{m}_{\mathrm{x}}$ of a given pollutant $\mathrm{x}$ emitted while producing the energy output $\mathrm{E}$ can be calculated as:

$$
\mathrm{m}_{\mathrm{x}}=\mathrm{u}_{\mathrm{x}}^{\mathrm{E}} \cdot \mathrm{E}
$$

where $u_{x}^{\mathrm{E}}$ is the energy output-based emission factor, that is, the specific emissions of $x$ per unit of $E$.

The mass of carbon dioxide equivalent emissions associated with the proposed and conventional systems was determined as reported below:

$$
\begin{gathered}
\mathrm{m}_{\mathrm{CO}_{2}}^{\mathrm{PS}}=\beta \cdot \mathrm{E}_{\mathrm{COS}, \mathrm{p}}+\alpha \cdot\left(\mathrm{E}_{\mathrm{EH}, \mathrm{el}}+\mathrm{E}_{\mathrm{SP}, \mathrm{el}}+\mathrm{E}_{\mathrm{RP}, \mathrm{el}}\right) \\
\mathrm{m}_{\mathrm{CO}_{2}}^{\mathrm{CS} 1}=\beta \cdot \mathrm{E}_{\mathrm{COS}, \mathrm{p}}+\alpha \cdot \mathrm{E}_{\mathrm{RP}, \mathrm{el}} \\
\mathrm{m}_{\mathrm{CO}_{2}}^{\mathrm{CS} 2}=\beta \cdot \mathrm{E}_{\mathrm{COS}, \mathrm{p}}+\alpha \cdot\left(\mathrm{E}_{\mathrm{EH}, \mathrm{el}}+\mathrm{E}_{\mathrm{RP}, \mathrm{el}}\right) \\
\mathrm{m}_{\mathrm{CO}_{2}}^{\mathrm{CS} 3}=\alpha \cdot\left(\mathrm{E}_{\mathrm{EH}, \mathrm{el}}+\mathrm{E}_{\mathrm{RP}, \mathrm{el}}\right)
\end{gathered}
$$

where is the $\mathrm{CO}_{2}$ equivalent emission factor for electricity production and represents the $\mathrm{CO}_{2}$ equivalent emission factor associated with coal-burning. According to the values suggested in [53] for the Mongolian scenario, the emission factor $\alpha$ was assumed to be equal to $1.06 \mathrm{~kg} \mathrm{CO} / \mathrm{kWh}_{\mathrm{el}}$ and the emission factor $\beta$ was considered of $0.78 \mathrm{~kg} \mathrm{CO}_{2} / \mathrm{kWh}_{\mathrm{p}}$.

The environmental comparison between the proposed and conventional systems was carried out by means of the following indicators:

$$
\begin{aligned}
& \Delta \mathrm{m}_{\text {coal }}=\left(\mathrm{m}_{\text {coal }}^{\mathrm{CS}}-\mathrm{m}_{\text {coal }}^{\mathrm{PS}}\right) / \mathrm{m}_{\text {coal }}^{\mathrm{CS}} \\
& \Delta \mathrm{CO}_{2}=\left(\mathrm{m}_{\mathrm{CO}_{2}}^{\mathrm{CS}}-\mathrm{m}_{\mathrm{CO}_{2}}^{\mathrm{PS}}\right) / \mathrm{m}_{\mathrm{CO}_{2}}^{\mathrm{CS}}
\end{aligned}
$$

where $\mathrm{m}_{\text {coal }}^{\mathrm{PS}}$ and $\mathrm{m}_{\mathrm{CO}_{2}}^{\mathrm{PS}}$ represent, respectively, the mass of coal and the mass of carbon dioxide equivalent emissions associated with the proposed system, while $\mathrm{m}_{\text {coal }}^{\mathrm{CS}}$ and $\mathrm{m}_{\mathrm{CO}_{2}}^{\mathrm{CS}}$ indicate the mass of coal and carbon dioxide equivalent emissions associated with the conventional systems.

\subsection{Economic Analysis}

The economic analysis was performed in terms of operating costs.

The operating costs of the proposed system were compared with those of the conventional systems by means of the following parameter:

$$
\Delta \mathrm{OC}=\left(\mathrm{OC}^{\mathrm{CS}}-\mathrm{OC}^{\mathrm{PS}}\right) / \mathrm{OC}^{\mathrm{CS}}
$$


where $\mathrm{OC}^{\mathrm{PS}}$ represents the operating costs associated with the proposed system and $\mathrm{OC}^{\mathrm{CS}}$ represents the operating costs associated with the conventional systems calculated as follows:

$$
\begin{gathered}
\mathrm{OC}^{\mathrm{PS}}=\mathrm{UC}_{\mathrm{coal}} \cdot \mathrm{m}_{\mathrm{coal}}+\mathrm{UC}_{\mathrm{el}} \cdot\left(\mathrm{E}_{\mathrm{EH}, \mathrm{el}}+\mathrm{E}_{\mathrm{SP}, \mathrm{el}}+\mathrm{E}_{\mathrm{RP}, \mathrm{el}}\right) \\
\mathrm{OC}^{\mathrm{CS} 1}=\mathrm{UC}_{\mathrm{coal}} \cdot \mathrm{m}_{\mathrm{coal}}+\mathrm{UC}_{\mathrm{el}} \cdot \mathrm{E}_{\mathrm{RP}, \mathrm{el}} \\
\mathrm{OC}^{\mathrm{CS} 2}=\mathrm{UC}_{\mathrm{coal}} \cdot \mathrm{m}_{\mathrm{coal}}+\mathrm{UC}_{\mathrm{el}} \cdot\left(\mathrm{E}_{\mathrm{EH}, \mathrm{el}}+\mathrm{E}_{\mathrm{RP}, \mathrm{el}}\right) \\
\mathrm{OC}^{\mathrm{CS} 3}=\mathrm{UC}_{\mathrm{el}} \cdot\left(\mathrm{E}_{\mathrm{EH}, \mathrm{el}}+\mathrm{E}_{\mathrm{RP}, \mathrm{el}}\right)
\end{gathered}
$$

where $\mathrm{UC}_{\text {coal }}$ is the unit cost of coal and $\mathrm{UC}_{\mathrm{el}}$ is the unit cost of electric energy. In this paper, the following constant values were assumed according to the Mongolian scenario: $\mathrm{UC}_{\mathrm{coal}}=0.048$ $€ / \mathrm{kg}_{\text {coal }}$ [54], $\mathrm{UC}_{\mathrm{el}}=0.053 € / \mathrm{kWh}_{\mathrm{el}}$ [55]. According to the new rules for electric energy utilization in the Ger district of Ulaanbaatar, the price of electricity is assumed equal to zero between midnight and 6.00 a.m.

In order to estimate the expected return on investment, the so-called simple pay-back period (SPB), i.e., the number of years required to recover the extra investment cost associated with the proposed system with respect to the reference systems, was calculated. It was defined as follows:

$$
\mathrm{SPB}=\left(\mathrm{CC}^{\mathrm{PS}}-\mathrm{CC}^{\mathrm{CS}}\right) /\left(\mathrm{OC}^{\mathrm{CS}}-\mathrm{OC}^{\mathrm{PS}}\right)
$$

where:

- $\quad \mathrm{CC}^{\mathrm{PS}}$ is the capital cost of the proposed system;

- $\quad \mathrm{CC}^{\mathrm{CS}}$ represents the capital costs of the conventional systems;

- $\mathrm{OC}^{\mathrm{PS}}$ is the operating cost of the proposed system due to the consumption of electricity and coal Equation (21);

- $\mathrm{OC}^{\mathrm{CS}}$ represents the operating costs of the conventional systems (Equation (22) for CS1, Equation (23) for CS2, Equation (24) for CS3).

The maintenance costs as well as the labor costs were neglected in calculating the values of SPB.

The capital costs of the proposed system $\mathrm{CC}^{\mathrm{PS}}$ and conventional systems $\mathrm{CC}^{\mathrm{CS}}$ were defined as reported below:

$$
\begin{gathered}
\mathrm{CC}^{\mathrm{PS}}=\mathrm{CC}^{\mathrm{SFC}}+\mathrm{CC}^{\mathrm{CO} \_6 \mathrm{~kW}}+\mathrm{CC}^{\mathrm{TES}}+\mathrm{CC}^{\mathrm{EH} \_3 \mathrm{~kW}}+\mathrm{CC}^{\mathrm{SP}}+\mathrm{CC}^{\mathrm{RP}} \\
\mathrm{CC}^{\mathrm{CS} 1}=\mathrm{CC}^{\mathrm{CO} \_9 \mathrm{~kW}}+\mathrm{CC}^{\mathrm{RP}} \\
\mathrm{CC}^{\mathrm{CS} 2}=\mathrm{CC}^{\mathrm{CO} \_6 \mathrm{~kW}}+\mathrm{CC}^{\mathrm{TES}}+\mathrm{CC}^{\mathrm{EH} \_3 \mathrm{~kW}}+\mathrm{CC}^{\mathrm{RP}} \\
\mathrm{CC}^{\mathrm{CS} 3}=\mathrm{CC}^{\mathrm{TES}}+\mathrm{CC}^{\mathrm{EH} \_9 \mathrm{~kW}}+\mathrm{CC}^{\mathrm{RP}}
\end{gathered}
$$

where:

- $\quad \mathrm{CC}^{\mathrm{SFC}}$ is the capital cost of the four series-connected evacuated tube heat pipe collectors (assumed equal to $12 € /$ tube, according to the values suggested by Ramos et al. [56], for a total cost of the entire solar field equal to $1440 €)$;

- $\mathrm{CC}^{\mathrm{TES}}$ is the capital cost of the thermal energy storage (assumed equal to $1000 €$, according to manufacturer data [57]);

- CC COS_6kW represents the capital cost of the $6 \mathrm{~kW}_{\text {th }}$ coal-burning stove (assumed equal to $190 €$, according to manufacturer data [44]);

- CC COS_9kW represents the capital cost of the $9 \mathrm{~kW}_{\mathrm{th}}$ coal-burning stove (assumed equal to $250 €$, according to manufacturer data [44]);

- $\quad C^{\mathrm{EH}} 3 \mathrm{~kW}$ is the capital cost of the $3 \mathrm{~kW}_{\text {el }}$ electric heater (assumed equal to $200 €$, according to manufacturer data [57]); 
- $\quad C^{\mathrm{EH}}-9 \mathrm{~kW}$ is the capital cost of the $9 \mathrm{~kW}_{\mathrm{el}}$ electric heater (assumed equal to $250 €$, according to manufacturer data [57]);

- $\quad \mathrm{CC}^{\mathrm{SP}}$ is the capital cost of the solar pump and controller (assumed equal to $360 €$, according to the values suggested by Ramos et al. [56]);

- $\quad \mathrm{CC}^{\mathrm{RP}}$ is the capital cost of the radiators pump (assumed equal to $167 €$, according to the values suggested by Ramos et al. [56]).

\section{Results and Discussion}

The proposed and reference systems were modelled and simulated in the TRNSYS environment (version 17) during the period running from 1 October to 31 May with a simulation time-step equal to two minutes.

The proposed system has been analyzed in the following two cases:

case (1) The dust deposition effects on the performance of the solar thermal collectors are neglected by assuming the glass tubes perfectly clean during the whole heating season;

case (2) The dust deposition effects on the performance of the solar thermal collectors are taken into account by means of Equation (2) as a function of the operating conditions.

Figure 10 indicates the daily average PM10 emissions $x_{i}$, the daily average wind factor $y_{i}$ (multiplied by 100), the daily average rain rate $z_{1, i}$ and the daily average snow rate $z_{2, i}$ measured by the authors in Ulaanbaatar during the period from October 2015 up to May 2016 [28] and used to run the simulations in this study in the above-mentioned case (2) with the dust deposition effects being taken into account. In the same figure, the percentage difference between the daily average glass tube transmittance including the effects of dust deposition $\tau_{\mathrm{w}, \text { dust }}$ (calculated based on Equation (2)) and the daily average glass tube transmittance without the dust deposition effects $\tau_{\mathrm{w} / \mathrm{o} \text {,dust }}$ (equal to 0.96 ) is reported as a function of the simulation time according to the experimental values of $x_{i}, y_{i}, z_{1, i}$ and $z_{2, i}$ :

$$
\Delta \tau=\left(\tau_{\mathrm{w}, \text { dust }}-\tau_{\mathrm{w} / \mathrm{o}, \text { dust }}\right) / \tau_{\mathrm{w} / \mathrm{o}, \text { dust }}
$$

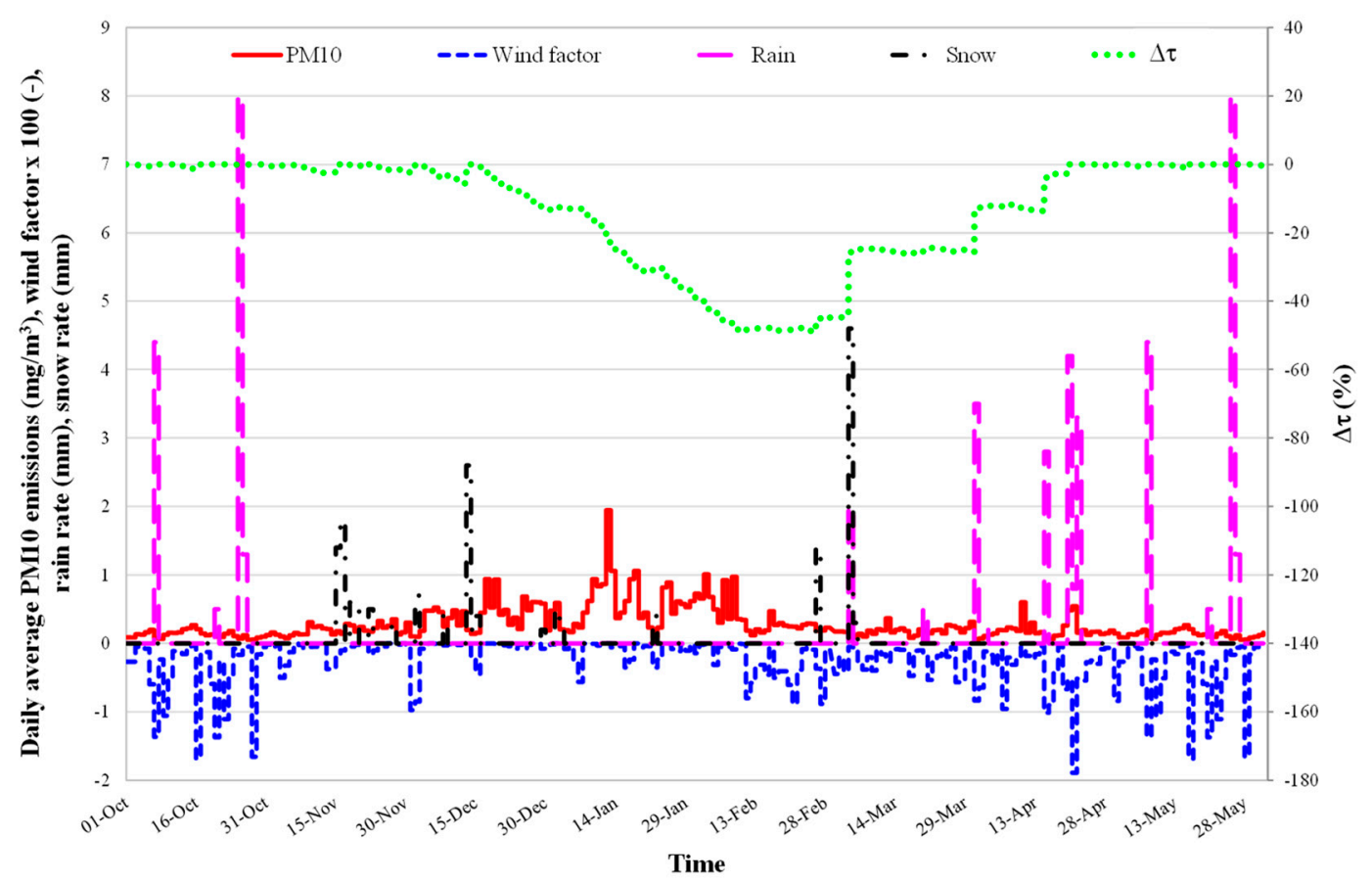

Figure 10. The experimental daily average PM10 emissions, wind factor, rain rate and snow rate in Ulaanbaatar from October 2015 up to May 2016, together with the percentage reduction of daily average glass tube transmittance due to the dust deposition. 
This figure highlights that rain is prevalent until the end of October, followed by snow from the middle of November until the beginning of March. After that, the rain starts again in March. In addition, it can be noted how the PM10 emissions during December, January and February are very significant (up to $2 \mathrm{mg} / \mathrm{m}^{3}$ ). Both rain and snow contribute to cleaning the tubes, while PM10 emissions reduce the transmittance of glass. The daily average wind factor (defined by Equation (3)) can be negative or positive: If the wind speed is high, $\mathrm{y}_{\mathrm{i}}$ becomes negative, meaning that the wind removes the dust from the tubes surface. In the case of the wind speed being low, $\mathrm{y}_{\mathrm{i}}$ is positive enhancing the dust deposition. In Figure 10, the values of $y_{i}$ are always negative. This means that the wind helps in cleaning the tubes as well as enhancing their transmittance during the whole heating season (mainly in October, April and May).

Figure 10 highlights that the combined effects of PM10 emissions, wind, rain and snow are substantial and reduce the nominal value of thermal transmittance without the dust deposition (0.96) by about $49.1 \%$. The reduction of $\tau$ is significant from the beginning of December up to the end of February due to the fact that PM10 emissions are relevant, while the contribution of rain, snow and wind in cleaning the tubes is limited.

Figure 11a,b describe the operation of the proposed plant (without the dust deposition effects) during a typical day (Sunday, 1 December), highlighting the daily trends of the thermal power recovered from the solar thermal collectors $\mathrm{P}_{\mathrm{SFC} \text {,th }}$, the thermal power delivered to the space heating circuit by the coal-burning stove $\mathrm{P}_{\mathrm{COS} \text {,th }}$, the thermal power provided by the electric heater $\mathrm{P}_{\mathrm{EH}}$,th, the control signal of the radiators pump (RP), the temperature level inside the house $\mathrm{T}_{\text {room }}$, the temperature difference $\Delta \mathrm{T}_{\mathrm{ON}}$, the temperature at the outlet of the coal stove $\mathrm{T}_{\mathrm{COS} \text {,out }}$, the temperature at the top of the thermal energy storage $\mathrm{T}_{\mathrm{TES} \text {,top, }}$, the outdoor temperature $\mathrm{T}_{\mathrm{amb}}$ as well as the temperature at the outlet of the solar field $\mathrm{T}_{\mathrm{SFC}, \text { out }}$ a function of the time.

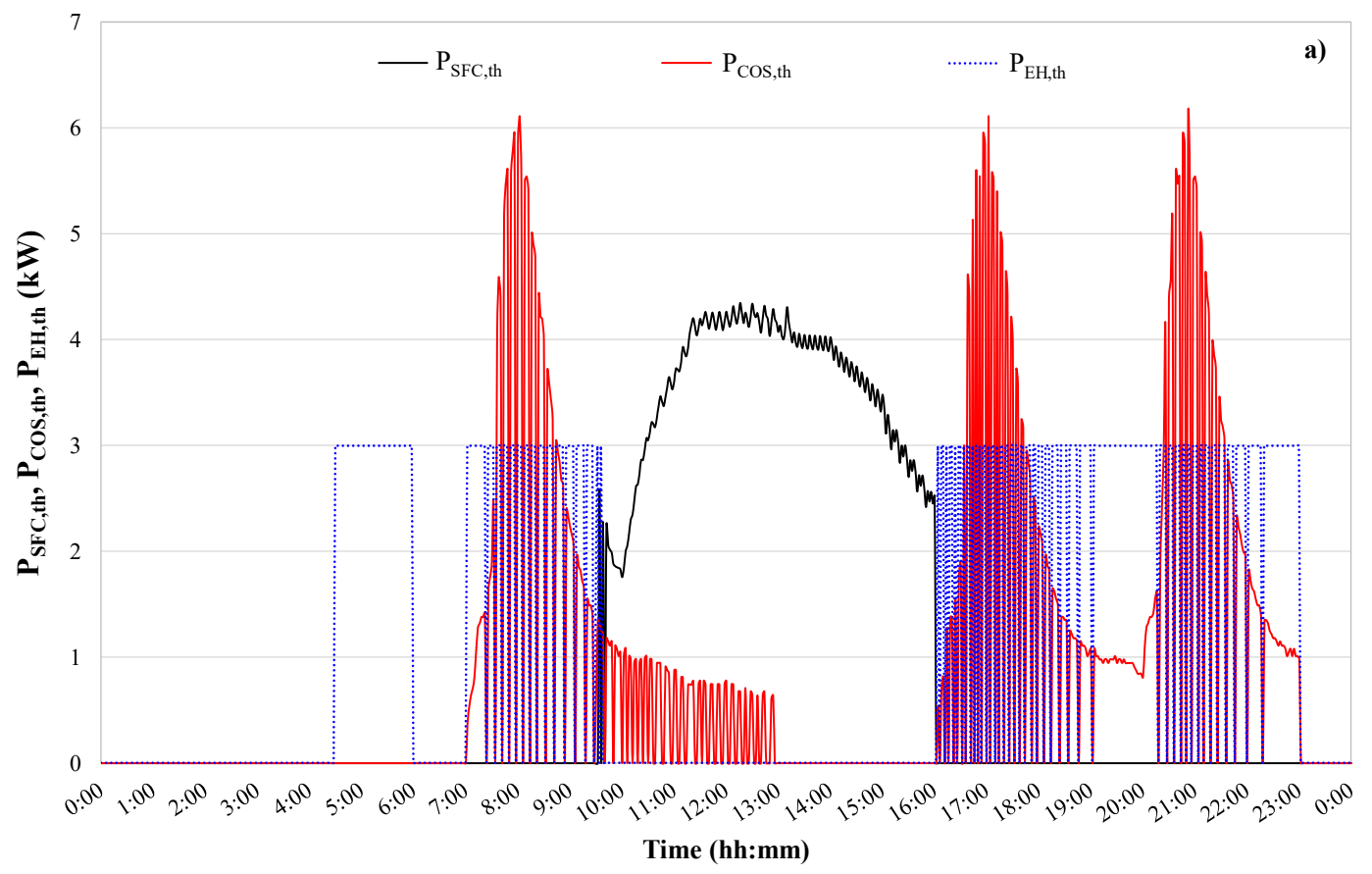

Figure 11. Cont. 


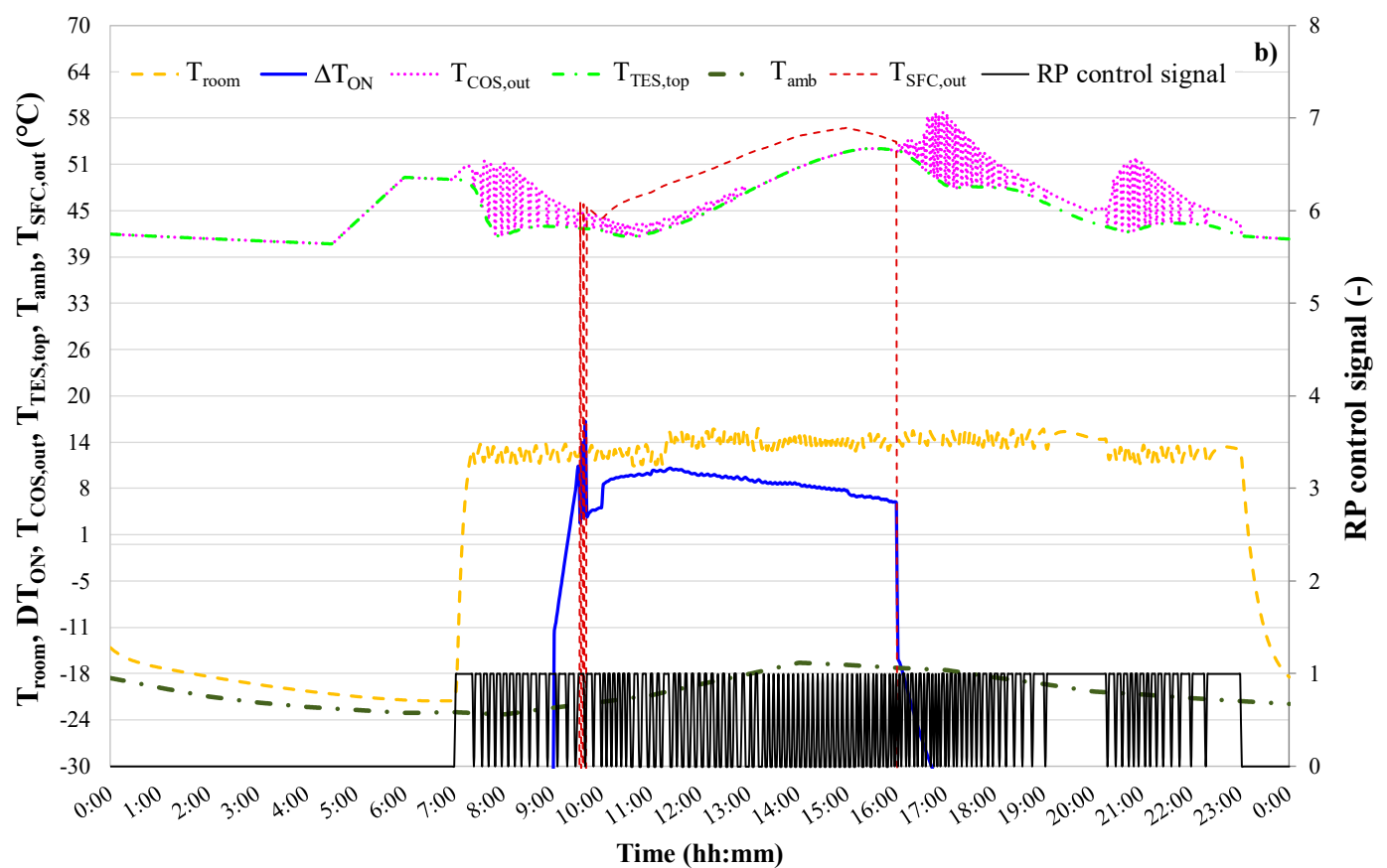

Figure 11. Thermal outputs (a) and the radiators circuit pump (RP) control signal together with temperature levels $(\mathbf{b})$ associated with the operation of the proposed system during a typical day (Sunday, 1 December).

From this figure, it can be derived that:

- The indoor air temperature $T_{\text {room }}$ is generally within the desirable thermal comfort levels indicated in Figure $4 \mathrm{~b}$ as a function of $\mathrm{T}_{\mathrm{amb}}$;

- Solar energy is recovered by the solar thermal collectors only from approximately 9:25 up to approximately 16:00, i.e., when the switch-on temperature difference $\Delta \mathrm{T}_{\mathrm{ON}}$ is higher than $8.0^{\circ} \mathrm{C}$. The solar circuit pump is switched off in the case of $\Delta \mathrm{T}_{\mathrm{ON}}$ becomes lower than $4.0^{\circ} \mathrm{C}$. The maximum thermal power recovered by the solar field is approximately $4.3 \mathrm{~kW}$, while the maximum temperature at the outlet of solar thermal collectors is equal to approximately $56^{\circ} \mathrm{C}$;

- The radiators circuit pump is switched on (RP control signal $=1$ ) when $\mathrm{T}_{\text {room }}$ falls below the user-specified set-point (Figure $4 \mathrm{~b}$ ) by $1.5^{\circ} \mathrm{C}$ and then is turned off ( $\mathrm{RP}$ control signal $=0$ ) when $\mathrm{T}_{\text {room }}$ exceeds the target (Figure $4 \mathrm{~b}$ ) by $1.5^{\circ} \mathrm{C}$;

- The coal-burning produces the thermal power reported in Figure 7a, but its thermal output is delivered to the space heating circuit only when the radiators pump is on ( $R P$ control signal $=1)$;

- The maximum temperature at the outlet of the coal-burning stove is $58.2^{\circ} \mathrm{C}$;

- The temperature at the top of the thermal energy storage is between $40.0^{\circ} \mathrm{C}$ and $53.4^{\circ} \mathrm{C}$ due to the contributions of the solar field, the electric heater as well as the stove.

Figure 12 reports the load-duration diagram associated with the entire heating season (characterized by a total duration of 5832 hours) with the heat-demand values sorted in descending order for the proposed plant (without the dust deposition effects). This figure shows how the space heating demand has a duration of approximately 1852 hours (equal to about $32 \%$ of the duration of the entire heating season), with the maximum thermal power transferred to the indoor air through the radiators being equal to approximately $17.3 \mathrm{~kW}$. 


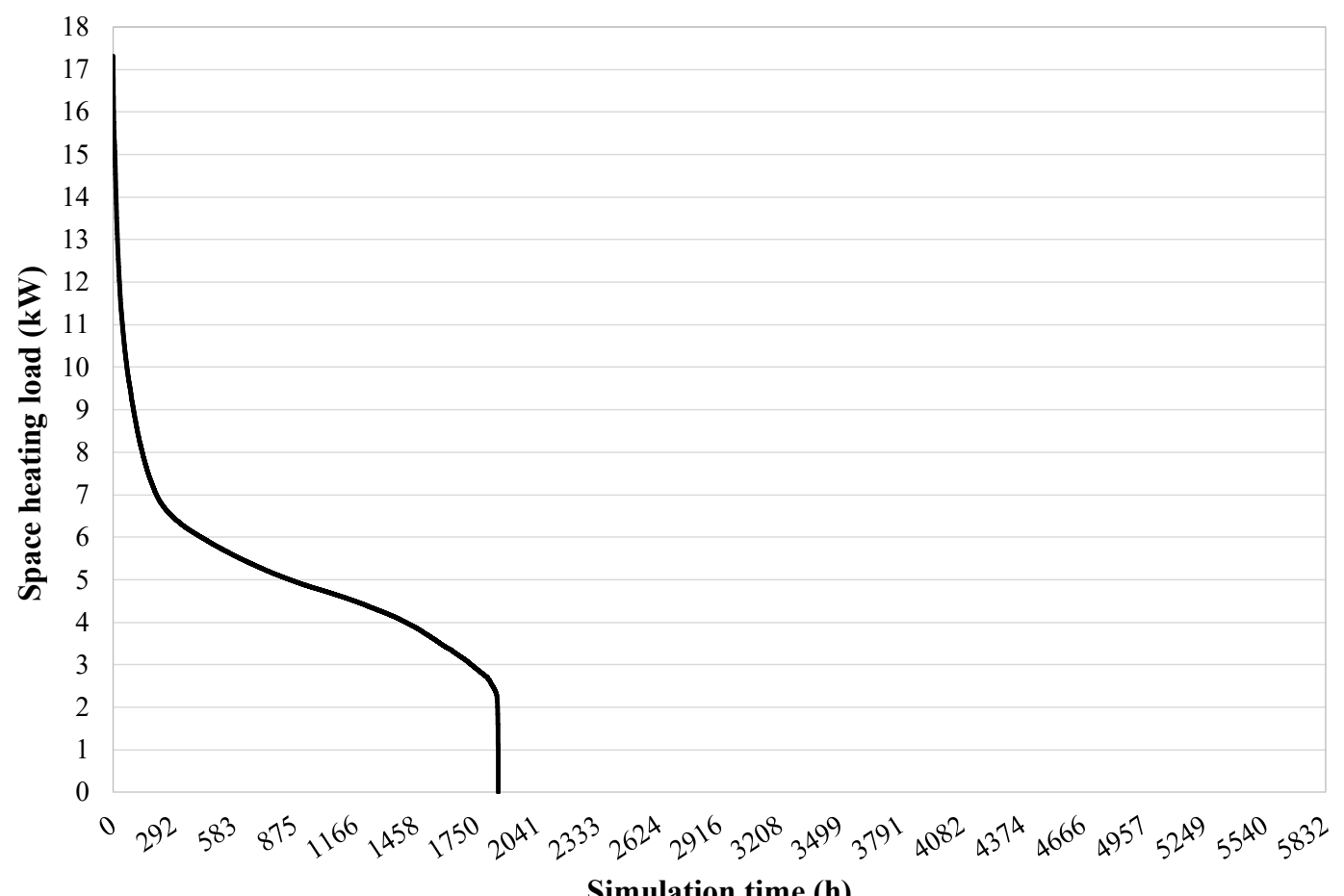

Figure 12. Space heating load-duration diagram for the proposed system without dust deposition.

Figure 13 indicates the energy flows associated with the whole simulation period from 1 October up to 31 May as a function of the plant configuration. The seasonal values of the thermal energy supplied to the house, the solar energy recovered by the solar thermal collectors and then transferred into the storage, the thermal energy delivered by the coal-burning stove to the heat carrier fluid, the thermal energy provided by the electric heater, the electric energy consumption of both the solar circuit pump and the radiators circuit pump as well as the total heat losses through the pipes of both the solar circuit and the radiators circuit are reported. With reference to the proposed system without the effects of dust deposition, Figure 13 shows that:

- The contribution of the solar source is significant when taking into account that the solar energy recovered from the solar thermal collectors and then injected into the storage is equal to approximately $38.0 \%$ of the total thermal energy supplied by the combination of solar source, electric heater and stove. The remaining thermal energy required for heating purposes is supplied by both the electric heater (by approximately $32.2 \%$ ) as well as the coal-burning stove (by approximately $29.8 \%$ );

- The electricity consumption of both pumps is not negligible, with it representing approximately $7.4 \%$ of the overall electric demand due to both pumps and electric heater (with the electric energy consumed by the radiators circuit pump approximately $27.6 \%$ greater than that one required by the solar circuit pump);

- The heat losses associated with the pipes of both the solar circuit as well as the radiators circuit are relevant (approximately $20.3 \%$ of the overall thermal energy demand of the house). 


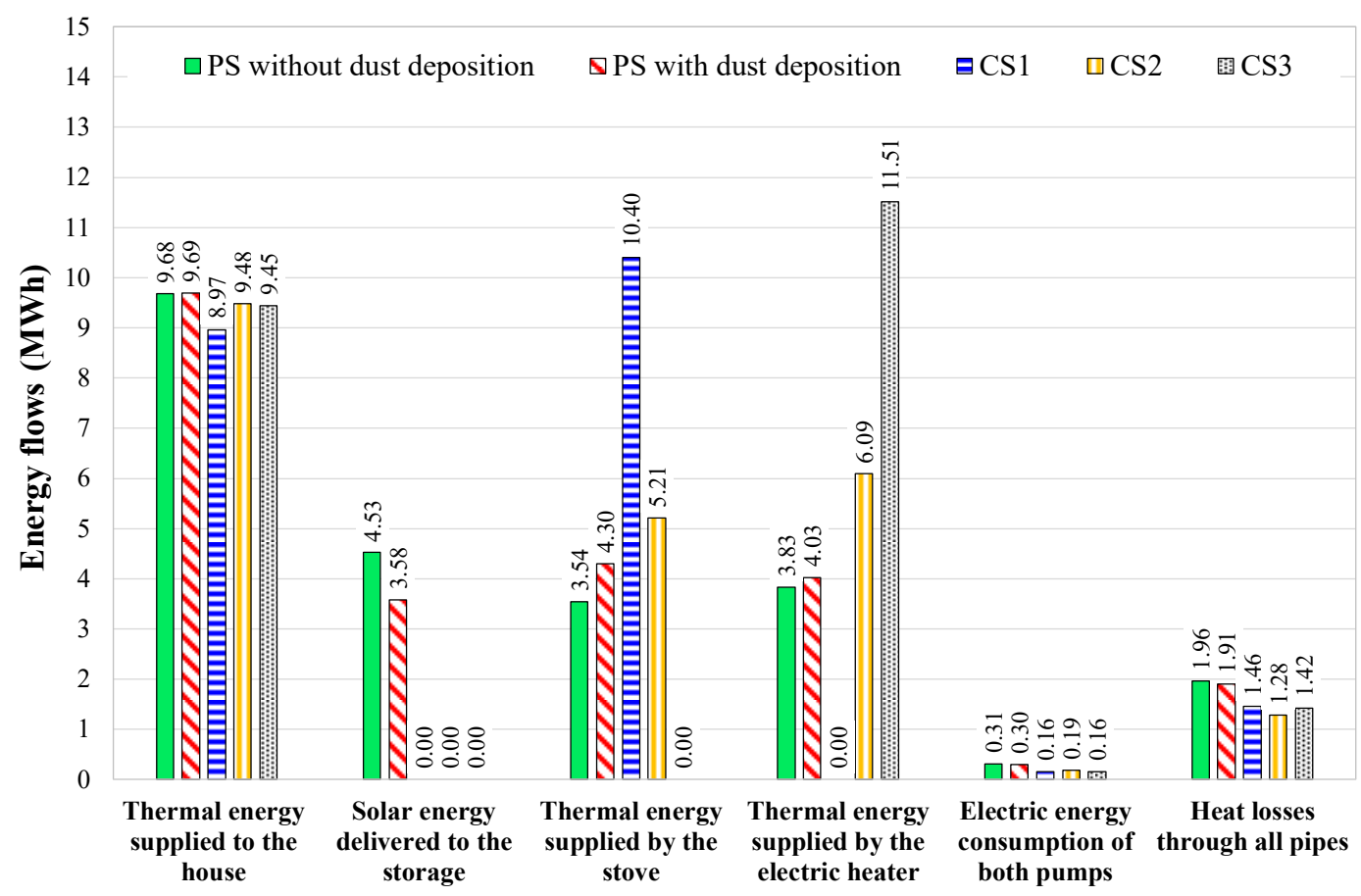

Figure 13. The energy flows associated with the operation of the proposed system (with and without dust deposition) as well as the conventional systems CS1, CS2 and CS3.

Figure 13 also highlights how, in comparison to the operation of the proposed system without considering the soiling effects, the impact of dust deposition significantly reduces the thermal energy recovered by the solar thermal collectors by approximately $-20.9 \%$, causing a greater consumption of both the electric heater (by approximately $+5.12 \%$ ) as well as the coal-burning stove (by approximately $+21.5 \%$ ).

This figure also indicates that, in the case of the conventional system CS2, the thermal energy demand of the house is mainly covered by the electric heater (by approximately $46.1 \%$ ), with the remaining energy supplied by the stove.

Figure 14a-c presents the single contributions of each component of the proposed system (with and without dust deposition) to the overall primary energy consumption (Figure 14a), $\mathrm{CO}_{2}$ equivalent emissions (Figure 14b) as well as the operating costs (Figure 14c) with reference to the entire heating season.

The amount of coal that is burned for heating purposes is, respectively, approximately $2610.0 \mathrm{~kg}$ with the tubes always clean and $3311.0 \mathrm{~kg}$ in the case of the effects of dust deposition are taken into account. In terms of primary energy consumption (Figure 14a), it can be stated that the $\mathrm{E}_{\mathrm{p}}$ associated with the stove is the largest part in the case with the dust. When the dust is neglected, the electric heater is mainly contributing to the overall $\mathrm{E}_{\mathrm{p}}$ consumption. Figure $14 \mathrm{~b}$ shows that the stove is in charge of the largest contribution in terms of carbon dioxide equivalent emissions. It is equal to approximately $69.6 \%$ and $65.4 \%$, respectively, with and without considering the soiling effects. The costs associated with the operation of the coal-burning stove represent approximately $44.8 \%$ (with the effects of the dust) and $40.2 \%$ (without the effects of the dust) of the overall operating costs of the proposed system (as highlighted in Figure 14c). 

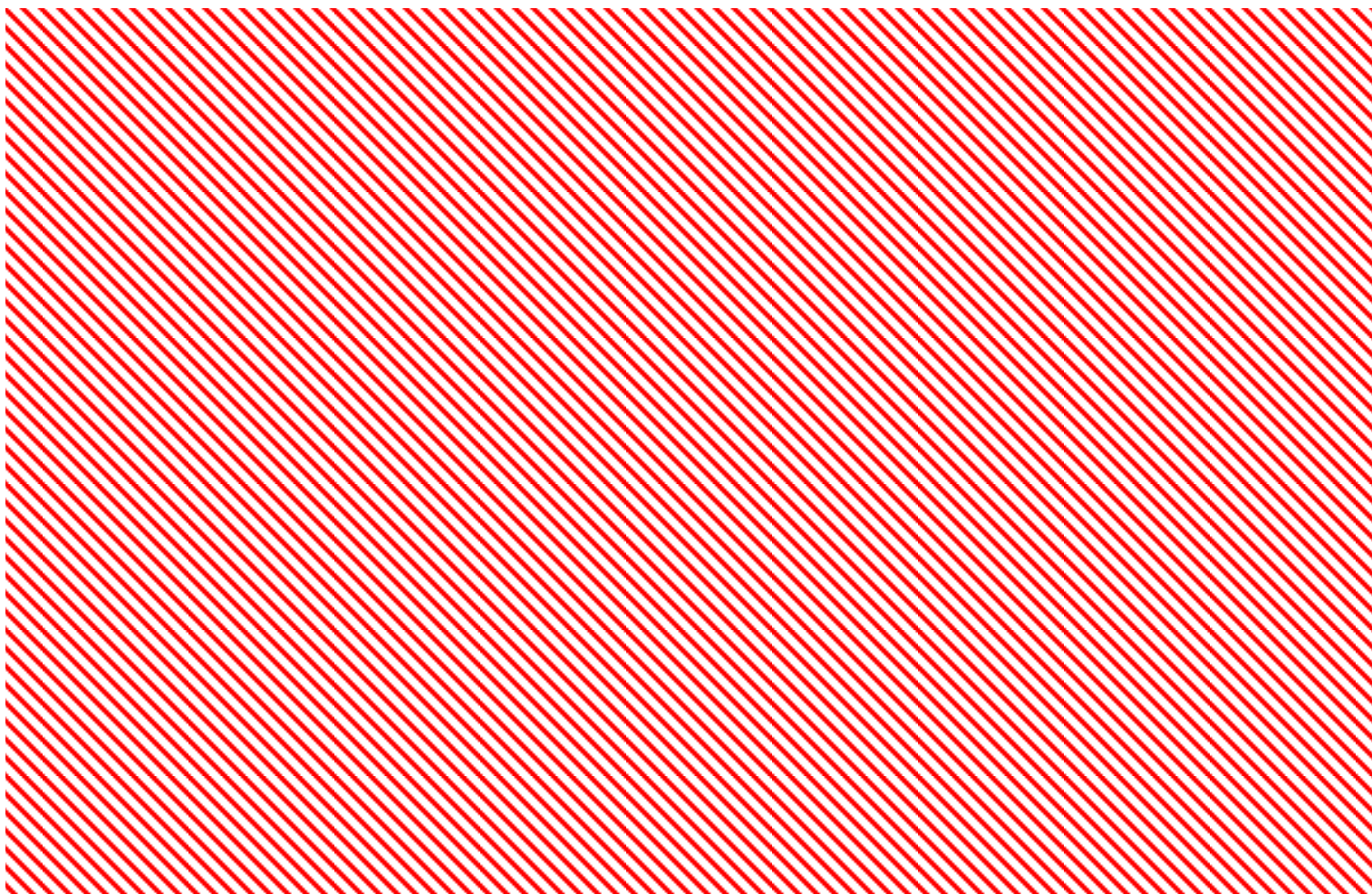

Figure 14. Primary energy consumption (a), $\mathrm{CO}_{2}$ equivalent emissions (b) and operating costs (c) associated with the components of the proposed system (with and without dust deposition effects) during the heating season.

Figure 15a-c report the seasonal values of PES (Equation (7)), $\Delta \mathrm{m}_{\text {coal }}$ (Equation (18)), $\Delta \mathrm{CO}_{2}$ (Equation (19)) and $\triangle \mathrm{OC}$ (Equation (20)) calculated by comparing the proposed system (with and without the effects of dust deposition) and the conventional systems CS1 (Figure 15a), CS2 (Figure 15b) and CS3 (Figure 15c). In Figure 15c, the values of $\Delta \mathrm{m}_{\text {coal }}$ are not indicated taking into account that coal is not used in the conventional system CS3.

Firstly, it should be highlighted that the simulation results indicate that the thermal comfort (house indoor air temperature within the desired temperature ranges) is guaranteed during approximately $95 \%$ of the entire simulation period for both the proposed plant (with and without considering the dust deposition effects) as well as the three reference systems by confirming that (i) the proposed and conventional systems are well designed/operated as well as (ii) they can be compared from the energy, environmental and economic points of view.
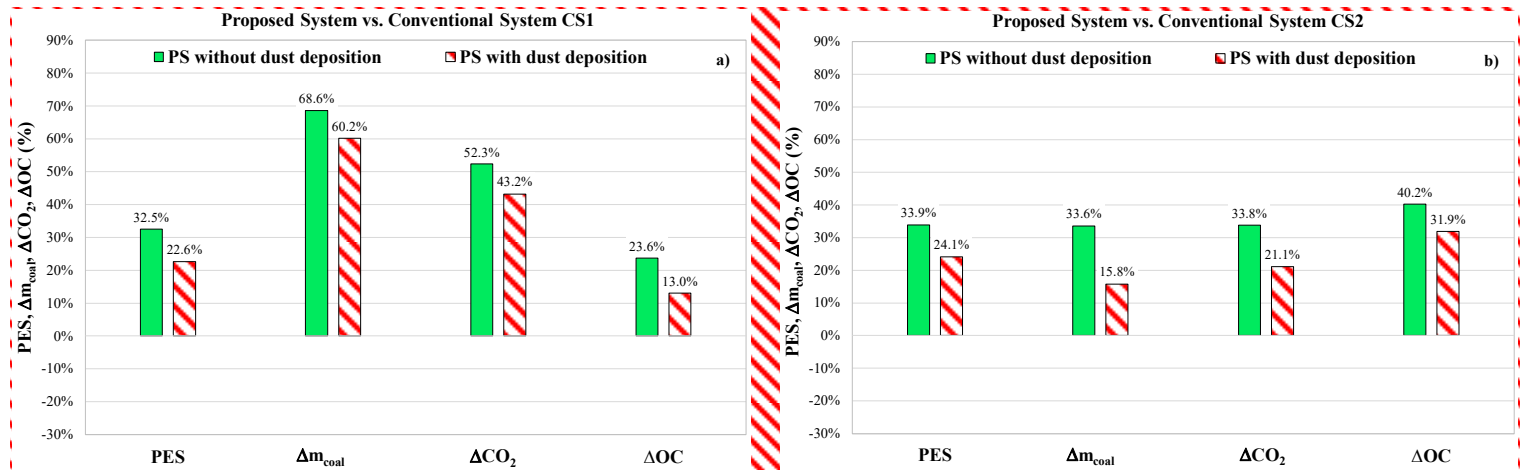

Figure 15. Cont. 


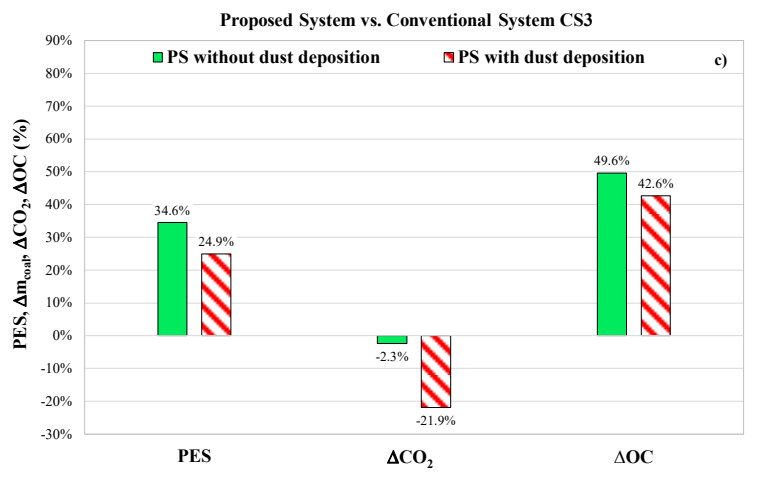

Figure 15. Seasonal values of primary energy saving (PES), $\Delta \mathrm{CO}_{2}, \Delta \mathrm{m}_{\text {coal }}$ and $\Delta \mathrm{OC}$ associated with the proposed system (with and without dust deposition effects) when compared with the conventional system CS1 (a), the conventional system CS2 (b) and the conventional system CS3 (c).

Figure 15a-c highlight that:

- The proposed system is able to achieve relevant reductions in terms of both the amount of coal that is burned as well as the carbon dioxide equivalent emissions in comparison to the conventional heating systems CS1 and CS2. In particular, the values of $\Delta \mathrm{m}_{\text {coal }}$ range from $15.8 \%$ up to $68.6 \%$, while $\Delta \mathrm{CO}_{2}$ is between $21.1 \%$ and $52.3 \%$. The maximum value of both $\Delta \mathrm{m}_{\text {coal }}$ and $\Delta \mathrm{CO}_{2}$ are obtained when the proposed system (without the dust deposition effects) is compared with the conventional system CS1, while both $\Delta \mathrm{m}_{\text {coal }}$ and $\Delta \mathrm{CO}_{2}$ assume the lowest values when the proposed system (with the soiling effects) is contrasted with the conventional system CS2;

- The conventional system CS3 is characterized by lower carbon dioxide equivalent emissions with respect to the proposed system, even if the total primary energy consumption of PS is lower than CS3. This is mainly due to the fact that the $\mathrm{CO}_{2}$ equivalent emission factor associated with the coal-burning $\left(0.78 \mathrm{~kg} \mathrm{CO}_{2} / \mathrm{kWh}_{\mathrm{p}}\right)$ is very high. In particular, the difference is negligible $\left(\Delta \mathrm{CO}_{2}=-2.3 \%\right)$ in the case of the soiling effects not being considered, but it becomes quite relevant $\left(\Delta \mathrm{CO}_{2}=-21.9 \%\right)$ when the impact of the dust deposition is taken into account;

- The proposed system significantly reduces the primary energy consumption (PES $>0$ ), whatever the conventional system assumed as a reference. In particular, the maximum PES $(+34.6 \%)$ is obtained when the proposed system (without the dust deposition effects) is compared with the conventional system CS3, while the minimum PES $(+22.6 \%)$ is achieved when the proposed system (with the soiling effects) is contrasted with the conventional system CS1;

- The proposed system is also able to reduce the operating costs by a percentage in the range $13.0 \% \div 49.6 \%$ (the maximum value of $\triangle \mathrm{OC}$ can be obtained in the case of the conventional heating system CS3 is assumed as a reference without considering the soiling effects, while the minimum saving in terms of operating costs relates to the case when the proposed system is contrasted with CS1 taking into account the effects of dust deposition);

- In comparison to the conventional system CS1 (that is the most common heating system in the Ger districts of Ulaanbaatar taking into account that $98 \%$ of the total households use only raw coal to satisfy the heating demand [1]), the proposed system obtains significant benefits due to the reduction of primary energy consumption by approximately $32.5 \%$, the amount of coal that is burned by approximately $68.6 \%$, the carbon dioxide equivalent emissions by approximately $52.3 \%$ and operating costs by approximately $23.3 \%$ in the case of the soiling effects not being considered;

- The impact of dust deposition on the overall energy, environmental and economic performance of the proposed system is very significant. In comparison to the performance of the proposed system with perfectly clean glass tubes, the soiling effect reduces the potential PES by approximately $9.7 \div 10.0 \%$, the potential $\Delta \mathrm{m}_{\text {coal }}$ by approximately $8.4 \div 17.8 \%$, the potential $\Delta \mathrm{CO}_{2}$ by approximately $9.1 \div 19.6 \%$ as well as the potential $\Delta \mathrm{OC}$ by approximately $7.0 \div 10.6 \%$. The most relevant effects of the dust deposition in terms of both PES $(-10.0 \%)$ and $\triangle \mathrm{OC}(-10.6 \%)$ 
can be recognized when the proposed system is compared with CS1. This clearly means that an appropriate cleaning strategy and timing of the solar field has to be identified in the future in order to fully exploit the potential benefits associated with the utilization of solar source.

Table 8 reports the values of the simple pay-back periods (SPB) as a function of the conventional system, assumed as a reference, with and without the dust deposition.

Table 8. Simple pay-back periods as a function of the conventional system.

\begin{tabular}{lcc}
\hline & Without Dust Deposition & With Dust Deposition \\
\hline PS vs. CS1 & 32.5 years & 61.9 years \\
PS vs. CS2 & 8.5 years & 10.7 years \\
PS vs. CS3 & 6.1 years & 7.1 years \\
\hline
\end{tabular}

This table highlights that:

- The duration of the simple pay-back period (32.5-61.9 years) is not acceptable when the proposed system is compared with the conventional system CS1 (mainly due to the capital costs of evacuated tube heat pipe collectors), so that significant economic incentives by the Mongolian Government supporting the application of solar collectors are strictly required;

- The values of SPB are reasonable when the proposed plant is contrasted with the reference systems CS2 and CS3, with the lowest values obtained when the case of the conventional plant CS3 is considered (6.1-7.1 years);

- The impact of dust deposition in terms of the simple pay-back period is relevant, with the values of SPB significantly increasing (from $16 \%$ up to $90 \%$ ) when the soiling effects are taken into account with respect to the case without the dust deposition.

\section{Conclusions}

In Mongolia, approximately $45 \%$ of the total population lives in the capital city of Ulaanbaatar and approximately $60 \%$ of the total households are located in the Ger districts of Ulaanbaatar, with approximately $98 \%$ of them using raw coal to satisfy the overall heating demand. The significant usage of raw coal during the winter leads to catastrophic air pollutant emissions, with Ulaanbaatar being one of the top 5 most polluted cities in the world. Even if solar energy is considered one of the most promising options for energy saving and reduction of harmful emissions at global and local levels, the exploitation of solar systems for heating purposes in cold regions has been poorly investigated up to now and further studies are necessary to explore its potential. In addition, almost no studies investigating the effects of the dust deposition on the performance of solar applications operating in cold areas with a great deal of air pollution (such as Mongolia) are available in current literature.

A solar hybrid heating system mainly consisting of a thermal energy storage, a solar field composed of four series-connected evacuated tube heat pipe collectors, an auxiliary electric heater, as well as a low-pressure coal-burning stove was modelled, simulated and analyzed by means of the commercial TRNSYS software platform (version 17) while satisfying the heating demand of a typical detached house situated in Ulaanbaatar (Mongolia).

The simulations results were compared with those associated with the operation of the following 3 different fossil fuel-based conventional heating systems (currently used in Mongolian residences) in order to assess the potential savings in terms of primary energy consumption, the amount of burned coal, carbon dioxide equivalent emissions as well as operating costs according to the Mongolian scenario:

- $\quad$ CS1: The conventional system is only equipped with a low-pressure coal-burning stove;

- CS2: The conventional system is equipped with a low-pressure coal-burning stove together with an electric heater installed inside a thermal energy storage; 
- CS3: The conventional system is only equipped with an electric heater immersed into a thermal energy storage.

The simulation results highlighted that:

- $\quad$ The proposed system (PS) allows the reduction of the primary energy as well as the operating costs in comparison to all the reference heating systems. The largest savings can be obtained when the performance of PS is contrasted with those associated with CS3;

- The proposed system is not convenient from an environmental point of view only with respect to the conventional system CS3. The largest savings in terms of global $\mathrm{CO}_{2}$ equivalent emissions are achieved in comparison to CS1;

- The expected return on the investment is not acceptable when the proposed system is compared with the conventional system CS1 (economic incentives supporting the application of solar systems are required), while it is reasonable with respect to the reference plants CS2 and CS3.

The main findings of the paper can be summarized in more detail as follows:

- in comparison to the Mongolian conventional heating systems assumed as references, the proposed system is potentially able to reduce the primary energy consumption by up to $34.6 \%$, the amount of burned coal by up to $68.6 \%$, the carbon dioxide equivalent emissions by up to $52.3 \%$ as well as the operating costs by up to $49.6 \%$;

- The proposed triple system allows a significant reduction of primary energy consumption (by approximately $32.5 \%$ ), the amount of coal that is burned (by approximately $68.6 \%$ ), the carbon dioxide equivalent emissions (by approximately $52.3 \%$ ) and the operating costs (by approximately $23.6 \%$ ) in comparison to the most common heating system (CS1) in the Ger districts of Ulaanbaatar [1];

- Using solar thermal collectors for heating purposes can contribute to covering a relevant percentage (approximately 38\%) of the heating demand of Mongolian residential applications;

- The effects of the dust deposition on glass tubes on the overall energy, environmental and economic performance of the proposed system are very relevant taking into account that the potential energy, environmental and economic savings are reduced from $7.0 \%$ up to $17.8 \%$ with respect to the case without the soiling effects. As a consequence, the cleaning strategy and timing of the solar collectors have to be investigated in more detail.

In order to facilitate the future implementation of the proposed system and support the decision-makers in carrying out the introduction of such plants, the authors would like to:

- Contrast the simulation results with the experimental data in order to assess the feasibility of the simulation models;

- Perform a sensitivity analysis with the aim of evaluating the effects of both the size and technology of both the solar collectors as well as the thermal energy storage on the overall energy, environmental and economic performance of the proposed system;

- Evaluate alternative control logics in order to find the one capable of maximizing the associated benefits;

- Define and assess different cleaning strategies of solar collectors in order to identify the one that allows for the maximization of the amount of energy provided by the solar technology for heating purposes.

Author Contributions: Conceptualization: A.R., P.E., A.C., A.A. (Atsushi Akisawa), A.A. (Amarbayar Adiyabat) and S.S.; data curation: A.R., P.E., A.C.; formal analysis: A.R., P.E., A.C. and A.A. (Amarbayar Adiyabat); funding acquisition: A.R., A.C. and S.S.; investigation: A.R., P.E., A.C. and A.A. (Amarbayar Adiyabat); methodology: A.R., P.E., A.C., A.A. (Atsushi Akisawa), A.A. (Amarbayar Adiyabat) and S.S.; project administration: A.R., P.E., A.C., A.A. (Atsushi Akisawa), A.A. (Amarbayar Adiyabat) and S.S.; resources: A.R., P.E., A.C., A.A. (Atsushi Akisawa), A.A. (Amarbayar Adiyabat) and S.S.; supervision: A.R., A.A. (Atsushi Akisawa), A.A. 
(Amarbayar Adiyabat) and S.S.; Validation: A.R., P.E., A.C., A.A. (Atsushi Akisawa), A.A. (Amarbayar Adiyabat) and S.S.; visualization: A.R., P.E., A.C.; writing-original draft: A.R., P.E., A.C., A.A. (Atsushi Akisawa), A.A. (Amarbayar Adiyabat) and S.S.

Funding: The APC was funded by the "V:ALERE 2019 program" of the University of Campania Luigi Vanvitelli (Italy).

Acknowledgments: For the publication of this article the authors would like to thank the "V:ALERE 2019 program" of the University of Campania Luigi Vanvitelli (Italy) that assigns contributions for the diffusion of open access research products.

Conflicts of Interest: The authors declare no conflicts of interest.

\section{Nomenclature}

\section{Latin letters}

\section{A}

$\mathrm{a}_{1}$

$a_{2}$

abs

B

C

c

$\mathrm{CC}$

$\mathrm{CO}_{2}$

$\mathrm{COS}$

CS

CS1

CS2

CS3

$\mathrm{D}$

E

$\mathrm{EH}$

f

G

$\mathrm{h}$

IHE

L

LHV

$\mathrm{m}$

$\mathrm{N}$

OC

$P$

PES

PM10

PS

Q

$\mathrm{R}$

RAD

RP

$\mathrm{S}$

SFC

$\mathrm{SP}$

SPB

STD area $\left(\mathrm{m}^{2}\right)$, empirically-derived constant $\left(\mathrm{m}^{3} / \mathrm{mg}\right)$

first order efficiency coefficient $\left(\mathrm{W} / \mathrm{m}^{2} \mathrm{~K}\right)$

second order efficiency coefficient $\left(\mathrm{W} / \mathrm{m}^{2} \mathrm{~K}^{2}\right)$

solar absorptance coefficient (-)

empirically-derived constant (-)

empirically-derived constant $\left(\mathrm{mm}^{-1}\right)$

specific heat $(\mathrm{kJ} / \mathrm{kgK})$

capital cost $(€)$

carbon dioxide

low-pressure coal-burning stove

conventional system

conventional system 1

conventional system 2

conventional system 3

empirically-derived constant $\left(\mathrm{mm}^{-1}\right)$

energy (kWh, kJ)

electric heater

function

global solar irradiance $\left(\mathrm{W} / \mathrm{m}^{2}\right)$

convective heat transfer coefficient $\left(\mathrm{W} / \mathrm{m}^{2} \mathrm{~K}\right)$

internal heat exchanger

empirically-derived constant (s/m)

lower heating value $(\mathrm{kJ} / \mathrm{kg})$

mass (kg)

number of experimentally investigated glass tubes (-)

operating cost $(€)$

power $(\mathrm{kW})$

primary energy saving (\%)

particles with aerodynamic diameters less than or

equal to $10 \mu \mathrm{m}$

proposed system

empirically-derived constant $(\mathrm{m} / \mathrm{s})$

measurand

radiator

radiators pump

thickness (m)

solar field collectors

solar pump

simple pay-back period (years)

Standard Temperature Difference $\left({ }^{\circ} \mathrm{C}\right)$ 
$\mathrm{T}$

$\mathrm{T}_{\mathrm{amb}}$

$\mathrm{T}_{\mathrm{m}}$

$\mathrm{T}_{\text {room }}$

$\mathrm{T}_{\text {room,target }}$

$\mathrm{T}_{\mathrm{TES}, 6}$

$\mathrm{T}_{\mathrm{TES}, \text { top }}$

$\mathrm{T}_{\mathrm{TES}, \text { top,target }}$

\section{TES}

U

UC

$\mathrm{u}$

$u_{x}^{E}$

$\mathrm{V}$

i

W

$\mathrm{X}$

$\mathrm{X}_{\mathrm{i}}$

$\mathrm{y}_{\mathrm{i}}$

$\mathrm{z}_{1, \mathrm{i}}$

$\mathrm{z}_{2, \mathrm{i}}$

Greeks

$\alpha$

$\beta$

$\Delta$

$\Delta \mathrm{T}_{\mathrm{ON}}$

$\eta$

$\eta_{0}$

$\lambda$

$\rho$

$\tau$

Superscripts/Subscripts

$\mathrm{CO}_{2}$

coal

COS

COS $6 \mathrm{~kW}$

COS_9kW

CS

CS1

CS2

CS3

dust

e

EH

EH_3kW

EH_9kW temperature $\left({ }^{\circ} \mathrm{C}\right)$

outdoor air temperature $\left({ }^{\circ} \mathrm{C}\right)$

average temperature between inlet and outlet of solar thermal collectors $\left({ }^{\circ} \mathrm{C}\right)$

indoor air temperature $\left({ }^{\circ} \mathrm{C}\right)$

set-point of indoor air temperature $\left({ }^{\circ} \mathrm{C}\right)$

temperature at node 6 of the thermal energy storage

$\left({ }^{\circ} \mathrm{C}\right)$

temperature at top layer (node 1 ) of the thermal

energy storage $\left({ }^{\circ} \mathrm{C}\right)$

target temperature at top layer (node 1) of the thermal energy storage $\left({ }^{\circ} \mathrm{C}\right)$

thermal energy storage

thermal transmittance $\left(\mathrm{W} / \mathrm{m}^{2} \mathrm{~K}\right)$

unit cost $\left(€ / \mathrm{kWh}_{\mathrm{el}}, € / \mathrm{kg}_{\text {coal }}\right)$

uncertainty

energy output-based emission factor $(\mathrm{kg} / \mathrm{kWh}, \mathrm{kg} / \mathrm{kJ})$

velocity $(\mathrm{m} / \mathrm{s})$

volumetric flow rate $\left(\mathrm{m}^{3} / \mathrm{h}\right)$

factor indicating the wind direction (-)

generic pollutant

daily average PM10 emissions during the ith day

$\left(\mathrm{mg} / \mathrm{m}^{3}\right)$

daily average wind factor during the ith day (-)

daily average rain rate during the ith day $(\mathrm{mm})$

daily average snow rate during the ith day $(\mathrm{mm})$

$\mathrm{CO}_{2}$ equivalent emission factor for electricity production $\left(\mathrm{kgCO}_{2} / \mathrm{kWh}_{\mathrm{el}}\right)$

$\mathrm{CO}_{2}$ equivalent emission factor of coal-burning

$\left(\mathrm{kgCO}_{2} / \mathrm{kWh}_{\mathrm{p}}\right)$

difference

switch on temperature difference $\left({ }^{\circ} \mathrm{C}\right)$

thermal efficiency

intercept efficiency

thermal conductivity $(\mathrm{W} / \mathrm{mK})$

density $\left(\mathrm{kg} / \mathrm{m}^{3}\right)$

glass tube transmittance (-)

carbon dioxide

coal

coal-burning stove

$6 \mathrm{~kW}$ coal-burning stove

$9 \mathrm{~kW}$ coal-burning stove

conventional system

conventional system 1

conventional system 2

conventional system 3

dust deposition on glass tubes

external

electric heater

$3 \mathrm{~kW}_{\mathrm{el}}$ electric heater

$9 \mathrm{~kW}_{\mathrm{el}}$ electric heater 


$\begin{array}{ll}\text { el } & \text { electric } \\ \text { frame } & \text { frame of windows } \\ \text { glazing } & \text { glazing of windows } \\ \text { i } & \text { internal } \\ \text { in } & \text { inlet } \\ \text { out } & \text { outlet } \\ \text { p } & \text { primary } \\ \text { PP } & \text { power plant } \\ \text { PS } & \text { proposed system } \\ \text { RP } & \text { radiators circuit pump } \\ \text { SFC } & \text { solar field collectors } \\ \text { SP } & \text { solar circuit pump } \\ \text { TES } & \text { thermal energy storage } \\ \text { th } & \text { thermal } \\ \text { w } & \text { water, with } \\ \text { wall } & \text { wall of the house } \\ \text { wg } & \text { mixture of water and ethylene glycol }(50 \% / 50 \% \text { by } \\ \text { window } & \text { volume }) \\ \text { w/o } & \text { window of the house }\end{array}$

\section{References}

1. World Bank Group. Mongolia-Heating Stove Market. Trends in Poor, Peri-Urban. Ger Areas of Ulaanbaatar and Selected Markets Outside Ulaanbaatar; Stocktaking Report of the Mongolia Clean Stoves Initiative (English); World Bank Group: Washington, DC, USA, 2013; Available online: http://documents.worldbank.org/curated/en/388091468323667110/Mongolia-Heating-stove-market-trendsin-poor-peri-urban-ger-areas-of-Ulaanbaatar-and-selected-markets-outside-Ulaanbaatar-stocktakingreport-of-the-Mongolia-clean-stoves-initiative (accessed on 27 June 2019).

2. Gheorghe, A.; Ankhbayar, B.; van Nieuwenhuyzen, H.; de Sa, R. Mongolia's Air Pollution Crisis: A Call to Action to Protect Children's Health; National Center for Public Health and UNICEF: Ulaanbaatar, Mongolia, 2018; Available online: https://www.unicef.org/mongolia/Mongolia_air_pollution_crisis_ENG.pdf (accessed on 13 August 2019).

3. Erdenedavaa, P.; Rosato, A.; Adiyabat, A.; Akisawa, A.; Sibilio, S.; Ciervo, A. Model analysis of solar thermal system with the effect of dust deposition on the collectors. Energies 2018, 11, 1795. [CrossRef]

4. Namjil, E. Overview of Energy/Electricity Demand and Renewable Energy Potential in Mongolia; Asia Super Grid Workshop: Seoul, Korea, 2016; Available online: https://www.renewable-ei.org/images/pdf/20160525/ Enebish_Namjil.pdf (accessed on 27 June 2019).

5. Pillarisetti, A.; Ma, R.; Buyan, M.; Nanzad, B.; Argo, Y.; Yang, X.; Smith, K.R. Advanced household heat pumps for air pollution control: A pilot field study in Ulaanbaatar, the coldest capital city in the world. Environ. Res. 2019, 176, 108381. [CrossRef] [PubMed]

6. Dawes, J.; Galbaatar, L.N. Domestic Solar Space Heating in Mongolia: Design and Demonstration. Environ. Eng. Renew. Energy 1998, 109-118. [CrossRef]

7. Bai, Y.; He, X.; Liu, Y.; Duan, J.; Wang, Y.; Hana, X. Experimental investigation of a solar thermal storage heater assembled with finned heat pipe and collective vacuum tubes. Energy Convers. Manag. 2018, 166, 463-473. [CrossRef]

8. Mori, T.; Kawamura, A. Design of Solar Water Heating System for Detached House in Cold Climate Area. Energy Procedia 2014, 48, 1393-1400. [CrossRef]

9. Zambolin, E.; Del Col, D. Experimental analysis of thermal performance of flat plate and evacuated tube solar collectors in stationary standard and daily conditions. Sol. Energy 2010, 84, 1382-1396. [CrossRef]

10. Kocer, A.; Atmaca, I.; Ertikin, C. A comparison of flat plate and evacuated tube solar collectors with f-chart method. J. Therm. Sci. Technol. 2015, 35, 77-86.

11. Najera-Trejo, M.; Martin-Domínguez, I.R.; Escobedo-Bretado, J.A. Economic feasibility of flat plate vs. evacuated tube solar collectors in a combisystem. Energy Procedia 2016, 91, 477-485. [CrossRef] 
12. Shuk, R.; Sumathy, K.; Erickson, P.; Gong, J. Recent advances in the solar water heating systems: A review. Renew. Sustain. Energy Rev. 2013, 19, 173-190. [CrossRef]

13. Ayompe, L.M.; Duffy, A. Thermal performance analysis of a solar water heating system with heat pipe evacuated tube collector using data from a field trial. Sol. Energy 2013, 90, 17-28. [CrossRef]

14. Abd-Elhady, M.S.; Nasreldin, M.; Elsheikh, M.N. Improving the performance of evacuated tube heat pipe collectors using oil and foamed metals. Ain Shams Eng. J. 2018, 9, 2683-2689. [CrossRef]

15. Nkwetta, D.N.; Smyth, M.; Haghighat, F. Experimental performance evaluation and comparative analyses of heat pipe and direct flow augmented solar collectors. Appl. Therm. Eng. 2013, 60, 225-233. [CrossRef]

16. Ong, K.S.; Tong, W.L. System performance of U-Tube and heat pipe solar water heaters. J. Appl. Sci. Eng. 2012, 15, 105-110.

17. Jack, S.; Katenbrink, N.; Schubert, F. Evaluation methods for heat pipes in solar thermal collectors e test equipment and first result. In Proceedings of the ISES Solar World Congress, Kassel, Germany, 28 August-2 September 2011.

18. Sarver, T.; Al-Qaraghuli, A.; Kazmerski, L.L. A comprehensive review of the impact of dust on the use of solar energy: History, investigations, results, literature, and mitigation approaches. Renew. Sustain. Energy Rev. 2013, 22, 698-733. [CrossRef]

19. Mani, M.; Pillai, R. Impact of dust on solar photovoltaic (PV) performance: Research status, challenges and recommendations. Renew. Sustain. Energy Rev. 2010, 14, 3124-3131. [CrossRef]

20. Adinoyi, M.J.; Said, S.A.M. Effect of dust accumulation on the power outputs of solar photovoltaic modules. Renew. Energy 2013, 60, 633-636. [CrossRef]

21. Saidan, M.; Albaali, A.G.; Alasis, E.; Kaldellis, J.K. Experimental study on the effect of dust deposition on solar photovoltaic panels in desert environment. Renew. Energy 2016, 92, 499-505. [CrossRef]

22. Zhao, J.; Wang, Z.; Wang, K.; Liu, J. Dust effect on thermal performance of flat plate solar collectors. J. Sol. Energy Eng. 2014, 137, 014502.

23. Hegazy, A.A. Effect of dust accumulation on solar transmittance through glass covers of plate-type collectors. Renew. Energy 2001, 22, 525-540. [CrossRef]

24. Cuddihy, E.F. Surface soiling: Theoretical mechanisms and evaluation of low soiling coatings. In Proceedings of the Flat-plate Solar Array Project Research Forum on Quantifying Degradation, Williamsburg, VA, USA, 6-8 December 1982.

25. El-Nashar, A.M. Effect of dust accumulation on the performance of evacuated tube collectors. Sol. Energy 1994, 53, 105-115. [CrossRef]

26. El-Nashar, A.M. Effect of dust deposition on the performance of a solar desalination plant operating in an arid desert area. Sol. Energy 2003, 75, 421-431. [CrossRef]

27. El-Nashar, A.M. Seasonal effect of dust deposition on a field of evacuated tube collectors on the performance of a solar desalination plant. Desalination 2009, 239, 66-81. [CrossRef]

28. Erdenedavaa, P.; Akisawa, A.; Adiyabat, A.; Otgonjanchiv, E. Observation and modeling of dust deposition on glass tube of evacuated solar thermal collectors in Mongolia. Renew. Energy 2019, 130, 613-621. [CrossRef]

29. TRNSYS. The Transient Energy System Simulation Tool. Available online: http://www.trnsys.com (accessed on 11 June 2019).

30. Antoniadis, C.N.; Martinopoulos, G. Optimization of a building integrated solar thermal system with seasonal storage using TRNSYS. Renew. Energy 2019, 137, 56-66. [CrossRef]

31. Shrivastava, R.L.; Kumar, V.; Untawale, S.P. Modeling and simulation of solar water heater: A TRNSYS perspective. Renew. Sustain. Energy Rev. 2017, 67, 126-143. [CrossRef]

32. Sibilio, S.; Rosato, A.; Ciampi, G.; Scorpio, M.; Akisawa, A. Building-integrated trigeneration system: Energy, environmental and economic dynamic performance assessment for Italian residential applications. Renew. Sustain. Energy Rev. 2017, 68, 920-933. [CrossRef]

33. Erdenedavaa, P.; Akisawa, A.; Adiyabat, A.; Otgonjanchiv, E. Performance analysis of solar thermal system for heating of a detached house in harsh cold region of Mongolia. Renew. Energy 2018, 117, 217-226. [CrossRef]

34. SketchUp Pro. Available online: https://www.sketchup.com/products/sketchup-pro (accessed on 11 June 2019).

35. ISO. EUROPEAN STANDARD EN ISO 6946:2007. Building Components and Building Elements-Thermal Resistance and Thermal Transmittance-Calculation Method; ISO: Switzerland, 2007. 
36. ISO. EUROPEAN STANDARD EN ISO 10077-1:2006. Thermal performance of Windows, Doors and Shutters-Calculation of Thermal Transmittance, Part 1: General; ISO: Switzerland, 2006.

37. Tong, J.C.-K.; Tse, J.M.-Y.; Jones, P.J. Development of thermal evaluation tool for detached houses in Mongolia. Energy Build. 2018, 173, 81-90. [CrossRef]

38. ISO. EUROPEAN STANDARD EN ISO 7730:2005. Ergonomics of the Thermal Environment-Analytical Determination and Interpretation of Thermal Comfort Using Calculation of the PMV and PPD Indices and Local Thermal Comfort Criteria; ISO: Geneva, Switzerland, 2005.

39. EnergyPlus. Weather Data. Available online: https://energyplus.net/weather-location/asia_wmo_region_2/ MNG//MNG_Ulaanbataar.442920_IWEC (accessed on 11 June 2019).

40. Jiangsu Sunrain Solar Energy Co. Available online: http://www.cccme.org.cn/shop/cccme6658/index.aspx (accessed on 11 June 2019).

41. Test Report, Thermal Performance of a Solar Collector. Available online: https://www.igte.uni-stuttgart. de/en/publications/publikationen-forschungs-und-testzentrum-fuer-solaranlagen-00001/dokumente_tzs/ jahresberichte_tests2010.pdf (accessed on 13 August 2019).

42. UNI. EUROPEAN STANDARD UNI EN 12975-2:2006, Thermal Solar Systems and Components-Solar Collectors_Part 2: Test Methods; UNI: Milan, Italy, 2006; Available online: http://store.uni.com/catalogo/ index.php/en-12975-2-2006.html?__store=en\&josso_back_to=http\%3A\%2F\%2Fstore.uni.com\%2Fjossosecurity-check.php\&josso_cmd=login_optional\&josso_partnerapp_host=store.uni.com\&_from_store=it (accessed on 11 June 2019).

43. Erdenedavaa, P.; Rosato, A.; Akisawa, A.; Adiyabat, A.; Ciervo, A.; Sibilio, S. Performance of solar collectors under Mongolian climatic conditions: Comparison between experimental and preliminary simulation results. In Proceedings of the Grand Renewable Energy 2018-International Conference and Exhibition, Pacifico Yokohama, Japan, 17-22 June 2018.

44. Гэрийн ба халаалтын зуух. Available online: https://www.slideshare.net/NCRAPM/academid-uguhhurliin-iltgel (accessed on 13 August 2019).

45. ALAVA. Available online: http://www.grupoalava.com/repositorio/13a0/pdf/6942/2/caudalimetroultrasonico-de-bajo-coste-portatil---a1tds.pdf?d=1 (accessed on 11 June 2019).

46. Eurotherm. Available online: https:/www.eurotherm.co.uk/products/sensors/resistance-temperaturedetector (accessed on 11 June 2019).

47. UNI. UNI CEI ENV 13005:2000. Guide to the Expression of Uncertainty in Measurement (GUM); UNI: Milan, Italy, 2000.

48. Mastrullo, R.M.A.; Rosato, A.; Vanoli, G.P.; Thome, J.R. A methodology to select the experimental plant instrumentation based on an a priori analysis of measurement errors and instrumentation cost. Int. Commun. Heat Mass Transf. 2008, 35, 689-695. [CrossRef]

49. Fondital Spa. Available online: http://www.fondital.com/ww/en/ (accessed on 11 June 2019).

50. Mongolian Energy Regulatory Commission. Statistics of Power System, Electricity Statistical Book; Mongolian Energy Regulatory Commission: Mongolia, Ulaanbaatar, 2014.

51. World Bank. Mongolia: Heating in Poor, Peri-Urban Ger Areas of Ulaanbaatar; Asia Sustainable and Alternative Energy Program; World Bank: Washington, DC, USA, 2009.

52. Chicco, G.; Mancarella, P. Assessment of the greenhouse gas emissions from cogeneration and trigeneration systems. Part I: Models and indicators. Energy 2008, 33, 410-417. [CrossRef]

53. IGES. List of Grid Emission Factors. Available online: https://pub.iges.or.jp/pub/list-grid-emission-factor (accessed on 11 June 2019).

54. Unegui.mn. Available online: https://www.unegui.mn/thrmzh-barilgyin-material-tlsh-thij-ed/tlee-nrstlsh/ ulan-bator/ (accessed on 11 June 2019).

55. Mongolian Energy Regulatory Commission. Available online: http://erc.gov.mn/index.php?newsid=675\# (accessed on 11 June 2019). 
56. Ramos, A.; Chatzopoulou, M.A.; Guarracino, I.; Freeman, J.; Markides, C.N. Hybrid photovoltaic-thermal solar systems for combined heating, cooling and power provision in the urban environment. Energy Convers. Manag. 2017, 150, 838-850. [CrossRef]

57. Paradigma. PS9000. Available online: http://www.paradigmaitalia.it/serbatoio-accumuloacqua-caldariscaldamento/boiler-accumulo-acqua-calda/accumulo-solaretermico (accessed on 30 July 2019).

(C) 2019 by the authors. Licensee MDPI, Basel, Switzerland. This article is an open access article distributed under the terms and conditions of the Creative Commons Attribution (CC BY) license (http://creativecommons.org/licenses/by/4.0/). 